\title{
Thyroid
}

\section{Thyrotropin receptor p.N432D retained variant is degraded through an alternative lysosomal/autophagosomal pathway and can be functionally rescued by chemical chaperones}

\begin{tabular}{|c|c|}
\hline Journal: & Thyroid \\
\hline Manuscript ID & THY-2020-0415.R2 \\
\hline Manuscript Type: & Clinical or Basic Original Study \\
\hline $\begin{array}{r}\text { Date Submitted by the } \\
\text { Author: }\end{array}$ & $n / a$ \\
\hline Complete List of Authors: & $\begin{array}{l}\text { Grassi, Elisa ; University of Milan, Medical Biotechnology and } \\
\text { Translational Medicine } \\
\text { Labadi, Arpad; University of Pecs Medical School, Department of } \\
\text { Laboratory Medicine } \\
\text { Vezzoli, Valeria; Istituto Auxologico Italiano Istituto di Ricovero e Cura a } \\
\text { Carattere Scientifico, Endocrinology } \\
\text { Ghiandai, Viola; Università degli Studi di Milano, Medical Biotechnology } \\
\text { and Translational Medicine } \\
\text { Bonomi, Marco; University of Milan, Medical Biotechnology and } \\
\text { Translational Medicine; Istituto Auxologico Italiano Istituto di Ricovero e } \\
\text { Cura a Carattere Scientifico, Endocrinology } \\
\text { Persani, Luca; Università degli Studi di Milano, Medical Biotechnology } \\
\text { and Translational Medicine; Istituto Auxologico Italiano Istituto di } \\
\text { Ricovero e Cura a Carattere Scientifico, Endocrinology and Metabolic } \\
\text { Diseases }\end{array}$ \\
\hline Keyword: & $\begin{array}{l}\text { Congenital Hypothyroidism, TSH Receptor, Thyroid Cell Biology, } \\
\text { Dishormonogenesis-Cell Biology }\end{array}$ \\
\hline \multirow[t]{2}{*}{$\begin{array}{r}\text { Manuscript Keywords (Search } \\
\text { Terms): }\end{array}$} & $\begin{array}{l}\text { TSH receptor, Congenital Hypothyroidism, autophagosome, Functional } \\
\text { rehabilitation, G protein coupled receptor, chaperone }\end{array}$ \\
\hline & $\begin{array}{l}\text { Background. Loss of function mutations of thyrotropin receptor (TSHR) } \\
\text { are one of the main causes of congenital hypothyroidism (CH). As for } \\
\text { many disease-associated GPCRs, these mutations often affect the correct } \\
\text { trafficking and maturation of the receptor, thus impairing the expression } \\
\text { on the cell surface. Indeed, several retained GPCR mutants are able to } \\
\text { effectively bind their ligands and to transduce signals when they are } \\
\text { forced to the cell surface by degradation inhibition or by treatment with } \\
\text { chaperones. Despite the large number of well-characterized retained } \\
\text { TSHR mutants, no attempts have been made for rescue. Furthermore, } \\
\text { little is known about TSHR degradation pathways. We hypothesize that, } \\
\text { similarly to other GPCRs, TSHR retained mutants may be at least } \\
\text { partially functional if their maturation and membrane expression is } \\
\text { facilitated by chaperones or degradation inhibitors. } \\
\text { Methods. We performed in silico predictions of the functionality of known } \\
\text { TSHR variants and compared the results with available in vitro data. } \\
\text { Western blot, confocal microscopy, ELISAs and dual luciferase assays }\end{array}$ \\
\hline
\end{tabular}


were used to investigate the effects of degradation pathways inhibition and of chemical chaperones treatments on TSHR variants maturation and functionality.

Results. Here, we report a high discordance rate between in silico predictions and in vitro data for retained TSHR variants, a fact indicative of a conserved potential to initiate signal transduction if these mutants were expressed on the cell surface. Indeed, we show for the first time experimentally that some maturation defective TSHR mutants are able to effectively transduce Gs/cAMP signaling if their maturation and expression are enhanced using chemical chaperones. Furthermore, through the characterization of the intracellular retained p.N432D variant, we provide new insights on TSHR degradation mechanism, as our results suggest that aggregation-prone mutant can be directed toward autophagosomal pathway instead of the canonical proteasome system.

Conclusions. Our study reveals alternative pathways for TSHR degradation. Retained TSHR variants can be functional when expressed on the cell surface membrane, thus opening the possibility of further studies on the pharmacological modulation of TSHR expression and functionality in patients in whom TSHR signaling is disrupted.

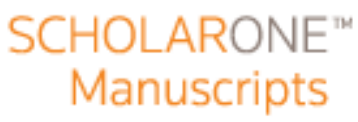


1 Thyrotropin receptor p.N432D retained variant is degraded through an alternative

2 lysosomal/autophagosomal pathway and can be functionally rescued by chemical chaperones

3 Elisa Stellaria Grassi ${ }^{1}$, Arpad Lábadi ${ }^{2 \#}$, Valeria Vezzoli ${ }^{3}$, Viola Ghiandai ${ }^{1}$, Marco Bonomi ${ }^{1,3}$,

4 Luca Persani ${ }^{1,3}$

5

61 Department of Medical Biotechnology and Translational Medicine, University of Milan, Milan, 7 Italy.

82 Department of Laboratory Medicine, University of Pécs, Pécs, Hungary.

93 Laboratory of Endocrine and Metabolic Research, Istituto Auxologico Italiano IRCCS, Milan, 10 Italy.

12 \# Current working address: Medicinkliniken, Centralsjukhuset Kristianstad CSK, Kristianstad, 13 Sweden.

Elisa Stellaria Grassi, MD, PhD.

ORCID: 0000-0002-0410-1277

BIOMETRA, Department of Medical Biotechnology and Translational Medicine, University of

18 Milan, Milan, Italy.

Phone: +3902619112432

Email: elehisie.rfm@gmail.com 
22 Arpad Lábadi, MD, PhD.

Department of Laboratory Medicine, University of Pécs, Pécs, Hungary.

26 Sweden.

Phone: +36202534616

Email: larpad81@gmail.com

Viola Ghiandai, MBiotech

ORCID: 000-0002-4595-986X

BIOMETRA, Department of Medical Biotechnology and Translational Medicine, University of Milan, Milan, Italy.

Phone: +3902619112432

Email: viola.ghiandai@unimi.it

Valeria Vezzoli, PhD.

38

ORCID: 0000-0001-6396-7284 
40

41

42

43

44

45

46

47

48

49

50

51

52

53

54

55

56

57

58 1

59 Email: luca.persani@unimi.it

Phone: +3902619113043

Email: valeriavezzoli@gmail.com

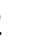

Marco Bonomi, MD, PhD.

ORCID: 0000-0001-5454-6074

BIOMETRA, Department of Medical Biotechnology and Translational Medicine, University of Milan, Milan, Italy.

Laboratory of Endocrine and Metabolic Research, Istituto Auxologico Italiano IRCCS, Cusano Milanino, Italy.

Phone: +3902619112390

Email: marco.bonomi@unimi.it

Luca Persani, MD, PhD.

ORCID: 0000-0003-2068-9581

BIOMETRA, Department of Medical Biotechnology and Translational Medicine, University of 5 Milan, Milan, Italy.

Laboratory of Endocrine and Metabolic Research, Istituto Auxologico Italiano IRCCS, Cusano 7 Milanino, Italy.

8 Phone: :+3902619112400 
63 Corresponding authors: Elisa Stellaria Grassi \& Luca Persani

65 Running title: TSHR variants degradation and functional rescue

67 Keywords: thyrotropin receptor, congenital hypothyroidism, G protein coupled receptor,

68 chaperone, autophagosome, functional rehabilitation 


\section{Abstract}

Background. Loss of function mutations of thyrotropin receptor (TSHR) are one of the main causes of congenital hypothyroidism $(\mathrm{CH})$. As for many disease-associated GPCRs, these mutations often affect the correct trafficking and maturation of the receptor, thus impairing the expression on the cell surface. Indeed, several retained GPCR mutants are able to effectively bind their ligands and to transduce signals when they are forced to the cell surface by degradation inhibition or by treatment with chaperones. Despite the large number of well-characterized retained TSHR mutants, no attempts have been made for rescue. Furthermore, little is known about TSHR degradation pathways. We hypothesize that, similarly to other GPCRs, TSHR retained mutants may be at least partially functional if their maturation and membrane expression is facilitated by chaperones or degradation inhibitors.

Methods. We performed in silico predictions of the functionality of known TSHR variants and compared the results with available in vitro data. Western blot, confocal microscopy, ELISAs and dual luciferase assays were used to investigate the effects of degradation pathways inhibition and of chemical chaperones treatments on TSHR variants maturation and functionality.

Results. Here, we report a high discordance rate between in silico predictions and in vitro data for retained TSHR variants, a fact indicative of a conserved potential to initiate signal transduction if these mutants were expressed on the cell surface. Indeed, we show for the first time experimentally that some maturation defective TSHR mutants are able to effectively transduce Gs/cAMP signaling if their maturation and expression are enhanced using chemical chaperones. Furthermore, through the characterization of the intracellular retained p.N432D variant, we provide new insights on TSHR degradation mechanism, as our results suggest that aggregation-prone mutant can be directed toward autophagosomal pathway instead of the canonical proteasome system. 
92 Conclusions. Our study reveals alternative pathways for TSHR degradation. Retained TSHR

93 variants can be functional when expressed on the cell surface membrane, thus opening the 94 possibility of further studies on the pharmacological modulation of TSHR expression and 95 functionality in patients in whom TSHR signaling is disrupted.

96

97 


\section{Introduction}

Loss of function (LOF) mutations of thyrotropin receptor (TSHR) are one of the principal causes of congenital hypothyroidism $(1,2)$. TSHR is a G-protein coupled receptor (GPCR) characterized by a seven transmembrane alpha-helix B-subunit and an extracellular A-subunit, linked by disulphide bonds $(3,4)$.

TSHR post-translational modifications are required for correct trafficking, maturation, and activity $(3,5,6)$. The N-linked glycosylation happening in the endoplasmic reticulum (ER) is fundamental (Fig. 1A): acquisition of mannose-type carbohydrates permits the interactions with molecular chaperones (Fig. 1B), required for correct receptor folding, homodimerization, passage through ER quality control system and translocation to cis-Golgi (Figure 1C) $(3,5,7)$. In trans-Golgi, TSHR finally acquires the complex-type carbohydrates (Fig. 1D) that characterize the mature form expressed on cell surface and undergoes tyrosine sulfation, fundamental for high-affinity binding and activation $(6,8)$. On plasma membrane TSHR is cleaved by an unidentified enzyme with loss of a short sequence of variable size, peptide C (Figure 1E). The receptor is finally composed by an extracellular A-subunit and a transmembrane B-subunit linked by disulfide bonds $(3,5,9,10)$.

For many disease-associated GPCRs, including TSHR, LOF is most often due to poor cell surface expression, rather than from intrinsic deficiencies in signal transduction. The abnormal mutant conformation leads to interactions with alternative molecular chaperones $(3,11,12)$, ER blockage and degradation by proteasome or by autophagosome (Fig. $1 \mathrm{G}, \mathrm{H})(13,14)$. Different retained GPCR mutants are able to effectively bind their ligands and transduce intracellular signals when forced to cell surface (15-17). The use of chemical chaperones is a well explored area to overcome ER retention of various membrane receptors (18-20). Nowadays, little is known about TSHR degradation pathways and no attempts have been made in TSHR mutants' rescue. 
121 The aim of our work is to better elucidate TSHR degradation pathways and the possibility of TSHR

122 mutants rescue with chemical chaperones. We concentrated our attention on two different mutants

123 that we previously described: the TSHR p.N432D, which is retained in the ER as high-mannose

124 form, and the p.P449L, that is normally expressed on plasma membrane but with impaired signaling 125 (21). We then validate our findings in two other retained TSHR mutants $(22,23)$.

126 Our results show for the first time that maturation-defective TSHR mutants are able to transduce 127 Gs/cAMP signaling when rescued by the chemical chaperone Trimethylamine-N-oxide (TMAO). 128 Moreover, we provide new insights on TSHR degradation mechanism, as our results suggest that 129 aggregation-prone mutants are directed toward the autophagosomal pathway instead of the 130 canonical proteasome system.

\section{Materials and Methods}

\section{Chemicals}

135 Cell culture reagents, ProLong Gold Antifade Reagent with DAPI, LysoTracker Red DND-99, ER136 Tracker Green, Alexa-Fluor conjugated and HRP-conjugated antibodies, Restore Western Blot 137 Stripping reagent were purchased from Thermo-Fisher. Mouse Anti-Actin Ab-5 was purchased 138 from BD Biosciences. Anti TSHR antibodies BA8 (Cat\#SC_BA8, RRID:AB_2716681), 3G4 139 (Cat\#SC_3G4, RRID:AB_2716682) and 28.1 (Cat\#SC_28.1, RRID:AB_2716683) were described 140 elsewhere (24-28) and were a kind gift from Dr S. Costagliola (IRIBHM, ULB, Brussels). Anti E141 Cadherin antibody was purchased from Abcam, anti VDAC was purchased from Santa Cruz. bTSH, 142 Anti-GFP antibody, TMAO, DMSO and MTT were purchased from Sigma-Aldrich. 


\section{In silico prediction}

TSHR variants membrane expression and functionality was assessed through the TSH receptor mutation database (29). 55 variants were subjected to in silico predictions and assigned as damaging or not damaging as specified in Supplementary Methods.

\section{Cell culture, transfection, treatments and viability assay}

COS-7 cells were grown in DMEM (Gibco) supplemented with 10\% fetal bovine serum (SigmaAldrich) and penicillin-streptomycin (Sigma-Aldrich). TSHR cloning and mutagenesis were described elsewhere (21). pSVL plasmids containing WT, p.E34K and p.R46P TSHR variants were a kind gift of Dr. Tonacchera $(22,23)$.

Transfection, degradation modulation and rescue were performed as described in Supplementary Methods. Cell viability was tested with MTT assay (30).

\section{Western blotting}

Cells were lysed in SDS buffer (62.5 mM Tris-HCl pH 6.8, 2\% sodium dodecyl sulfate) supplemented with protease, phosphatase and proteasome inhibitors.

Membrane preparations were obtained with Plasma Membrane Protein Extraction Kit (Abcam)

following manufacturer's instructions. Total Cellular Membranes and Plasma Membranes fractions were then processed as the other samples, as described in Supplementary Methods.

Band intensity was quantified with ImageJ software (31).

\section{Immunofluorescence and Confocal Microscopy}


Samples were processed as previously described (32), and detailed in Supplementary Methods.

167 Images were acquired with EclipseTi-E inverted microscope with IMA10X Argon-ion laser System 168 by Melles Griot; images were acquired with CFI Plan Apo VC 60X Oil (Nikon).

Samples were processed as previously described (32), and detailed in Supplementary Methods.

Measurements were performed with FACSCalibur flow cytometer (Becton Dickinson). Data were analyzed with Flowing Software 2.

\section{Functional assays}

cAMP pathway activity was assessed with Cignal CRE Reporter (luc) Kit (Quiagen), while

177 Gq11/IP3 pathway activity was measured with IP-One ELISA assay kit (Cisbio), following 178 manufacturer's instructions, as described in Supplementary Methods.

\section{Statistical analysis}

181 All experiments were independently repeated at least three times, as indicated in the figure legends.

182 After normal distribution and variance similarity evaluation, two-sided unpaired t-test (eventual

183 Welch's correction for groups with different variances), one-way ANOVA with Bonferroni post-

184 hoc test, Kruskal-Wallis H test with Dunns post hoc test and Chi-square test were used as indicated 185 in figures' legend. 
For concentration-effect curves of Gs/cAMP signaling a log(agonist) vs. normalized response Variable slope equation was used for curve interpolation and parameters definition.

For confocal experiments, the degree of colocalization was quantified through Pearson's correlation coefficient, as measured with Nikon NIS Elements software. Correlation was defined as strong with Pearson's correlation coefficient bigger than 0.8 , moderate when bigger than 0.5 and weak when bigger than 0.2 .

In all figures data are shown as mean \pm SEM, analyzed using GraphPad Prism 5 software and significance expressed as $\mathrm{P}$ values $(* \mathrm{p}<0.05, * * \mathrm{p}<0.01, * * * \mathrm{p}<0.001)$.

\section{Results}

\section{In silico prediction and in vitro data of receptor functionality are significantly discordant in} retained mutants

We obtained complete information about in vitro functionality and subcellular localization of 55

LOF TSHR variants (29) and categorize them as intracellular-retained or membrane-expressed

\section{(Suppl. Table 1).}

These mutations were subjected to in silico predictions and assigned as functional or non-

functional. The comparison of in vitro and in silico data reveals significantly higher discordance rate among the retained group (12/24 and 7/31 mutants with positive prediction but in vitro LOF for intracellular-retained and membrane-expressed respectively, $p=0.0471)$ (Table 1).

\section{Such discrepancy may indicate that some ER retained mutants can potentially transduce signal if}

\section{expressed on cell surface.}


206 We thus explored the degradation mechanisms and chaperone rescue on two previously reported 207 (21) TSHR LOF variants: the intracellular-retained p.N432D and the membrane-expressed 208 p.P449L.

\section{N432D variant is arrested in the ER and forms different aggregates}

211 We performed confocal microscopy with two different antibodies, the BA8 directed against a 212 conformational epitope on the mature A-subunit and the 3G4 raised against a linear epitope in the 213 C-peptide that recognizes principally immature forms $(24,25)$.

WT TSHR and p.P449L variant have a normal membrane expression in all transfected cells (Fig. 2 A), whereas p.N432D have a variable pattern detected by BA8 antibody, with three main morphologies: small intracellular aggregates (SA), perinuclear signal (PS) and cytoplasmic macroaggregate (MA) (Fig. 2 B). SA and PS are the most frequent ones, while in around 10\% p.N432D pattern has the characteristics of more than one morphology (mixed morphology, MM)

(Fig. 2 C). In contrast, p.N432D variant staining with 3G4 antibody reveals a constant pattern of diffuse perinuclear signal that is not detectable with BA8 antibody (Fig. 2 B, second lane). This difference may indicate the presence of a significant amount of immature or incorrectly folded receptors recognized only by $3 \mathrm{G} 4$ antibody but not by BA8 (24).

Interestingly, SA are similar to the puncta that characterize misfolded GPCR mutants degraded by autophagocytosis $(33,34)$, while MA are suggestive of perinuclear aggregates related to the proteasome degradation pathway $(34,35)$. majority of the protein recognized by $3 \mathrm{G} 4$ antibody is indeed localized in the ER (Fig. 2 D, E). 
transfected cells. On the other hand, the aggregates recognized by BA8 antibody show a mild colocalization with endosomes/lysosomes (Fig. 2 F, G).

\section{TSHR mutants are degraded through different pathways}

For many GPCRs, ubiquitin-proteasome system is the main degradation system $(37,38)$, while mutants prone to form aggregates are directed toward autophagic degradation $(33,39)$. We evaluated if that was our case by performing western blot in different conditions, with the 28.1 antibody that recognizes full length receptor at different stages of maturation together with the cleaved A-subunit $(28,40)$.

MG132 proteasome inhibitor induces a significant accumulation of mature WT TSHR and p.P449L variant, confirming the fundamental role of this pathway. However, only a strong accumulation of the immature form is detected for p.N432D (Fig. $3 \mathrm{~A}, \mathrm{~B}$ ). $\mathrm{NH}_{4} \mathrm{Cl}$ autophagocytosis inhibitor does not cause significant alterations in the total WT TSHR, although a change in the amount of mature forms can be appreciated, as previously reported (5). On the other hand, endolysosomal inhibition induces a more effective accumulation of p.P449L and of immature p.N432D than the proteasomal one (Fig. 3. A, B). Confocal microscopy experiments reveal significant increase in SA after autophagocytosis inhibition, while a significant increase in MA is seen after proteasome inhibition; concomitant inhibition has indeed an intermediate effect (Fig. 3 C), thus confirming western blot data.

Autophagocytosis activation with $\mathrm{LiCl}$ induces an almost complete degradation of p.N432D variant, with milder effects on p.P449L and no effects on WT (Fig. 3 D, E). Moreover, only p.N432D expression induces JNK 1/2 phosphorylation, an event linked to autophagocytosis activation (41), and significantly reduces cell viability (Suppl. Fig. 1 A, B), thus confirming the role of autophagocytosis in misfolded TSHR degradation. 
The chemical chaperone TMAO restores p.N432D mutant membrane expression.

p.N432D mutant does not maturate even if protein degradation is inhibited, but as immature TSHR can signal when expressed on plasma membrane $(42,43)$, we investigated whether this was our case by the use of different chemical chaperones.

Western blot experiments show that, unlike in other GPCRs (44), treatment with glycerol is not effective in p.N432D variant rescuing (Suppl. Fig. 3). Nevertheless, TMAO treatment (45) increases the maturation of all TSHR variants, but with major effects on p.N432D whose A subunit intensity reaches levels similar to WT control indicating possible membrane expression, while the high mannose form has a larger increase in the WT and p.P449L (Fig. 4 A, B). The hybridization with 3G4 antibody reveals that TMAO treatment causes a significant increase in a high molecular weight band (around 200 kDa) (Suppl. Fig. 2 A, B) which has been identified as dimers of high mannose forms (43), whose formation is fundamental for passage through ER quality control.

FACS experiments in non-permeabilized cells confirmed cell-surface expression of TMAO treated

p.N432D. Interestingly, membrane expression resulted 75\% of WT control with BA8 antibody

(Fig. 4 C, D), and only around 50\% of WT control with 3G4 antibody (Fig. 4 E, F) with a BA8:3G4 ratio of $1.62 \pm 0.25(\mathrm{p}<0.05 v s$ treated WT), a finding that indicates increased cleavage of the p.N432D mutant (25).

Immunofluorescence experiments with BA8 staining confirm p.N432D membrane expression after TMAO treatment. The increase in intracellular staining for TMAO-treated TSHRs is in agreement with the increase in immature forms detected at western blot experiments (Fig. 4 G).

Cellular membranes fractionations revealed that the A subunit is the predominant form on the cell surface. Moreover, TMAO promotes WT TSHR translocation on the cell surface, as we detected a 
275 decrease in the levels of all TSHR maturation forms in the total membrane extracts and an increase in the plasma membrane extracts. This effect is not seen in the p.P449L variant, that is also insensible to TMAO effects (Suppl. Fig. 2 C, D).

Membrane expression uncovers the functional potential of p.N432D and other retained variants.

Gq11/IP3 pathways revealed that indeed the mutant is partially functional when expressed on plasma membrane. In fact, although Gq11/IP3 pathway remains greatly compromised (Fig. 5 A), the maximal Gs/cAMP response is almost completely rescued (Fig. 5 B). Concentration-effect curves (Fig. 5 C, Suppl. Fig. 4 A and Table 2) show that TMAO treatment has virtually no effect on the Gs/cAMP signaling of either the WT or p.P449L mutant receptor, while the TMAO-treated p.N432D curve is right-shifted, indicating higher EC50 values.

As last step, we investigated two additional retained variants that have discordant in silico and in vitro functionality: the p.E34K, that has a reported membrane expression of $30 \%$ of WT, and the p.R46P that is reported to be almost totally retained and with very low ability to signal through the cAMP pathway $(22,23)$.

TMAO treatment induces an increase in the cleaved A-subunit levels in the p.E34K variant and greatly enhances the maturation of the retained p.R46P one (Fig. 5 E, D), with effects similar to the ones observed in p.N432D. Accordingly, functional assays reveal a significant increase in both p.R46P (Fig. 5 F, G), with concentration-effect curves and EC50 similar to those of the WT (Fig. 5 H). 


\section{Discussion}

In the present work, we reveal two important issues regarding the possible intracellular destiny of the folding-defective TSHR mutants. First, they may be degraded not only through the proteasomal pathway, but also through an alternative autophagosomal-like pathway that kicks in as emergency exit after retention in the ER. Second, they can at least partially function if forced to the cell surface by using chemical chaperones. Our data provide a possible explanation for the observed lack of concordance between in silico prediction of receptor functionality and in vitro findings, as misfolded mutants that retain signaling abilities may have a premature maturation arrest, intracellular retention and subsequent degradation.

The involvement of the lysosomal system in the degradation of misfolded TSHR mutants is a new interesting finding. In particular, p.N432D has such structural changes that prevent passing the ER quality control. In the ER the mutant is likely to form aggregates, microscopically detected as SA pattern, that cannot be retro-translocated to the cytoplasm where proteasome operates, but are instead degraded by alternative autophagocytosis (Fig.1,2, 3 and Suppl. Fig. 1); a behavior similar to the one previously described for gonadotropin releasing-hormone receptor (GnRHR) mutant p.E90K (33).

The treatment with TMAO is likely inhibiting the formation of ER aggregates while promoting the receptor homodimerization, sheltering p.N432D from ER quality control and allowing advancement to Golgi compartment and finally to plasma membrane $(3,46)$, as also indicated by the appearance of the A-subunit bands in plasma membrane preparations. Nevertheless, its maturation does not seem to follow the regular steps even after TMAO treatment as we detected very low levels of complex carbohydrates form (Fig. 4A and 4B).

There are two possible explanations of this issue. The first and most likely hypothesis is that only a small percentage of plasma membrane p.N432D mutant reach full maturation, while most of it is 

still blocked at the high-mannose stage. Membrane expression of immature TSHR has already been described $(26,42,43,47)$ and TSHR with reduced glycosylation sites has TSH binding affinity and EC50 for cAMP that are indistinguishable from the mature one (3). In this case, the p.N432D

maturation limiting factor may be the ability to form dimers in the ER compartment, as the staining with 3G4 antibody promptly showed a significant increase in the levels of immature TSHR dimers after TMAO treatment (Suppl. Fig. 2 A, B). The increased cleavage indicated by the variation in BA8:3G4 ratio (Fig. 4 C, E, Table 2) can then be explained by the already known higher sensitivity to proteases action of immature $\operatorname{TSHR}(25,42)$.

The second possible explanation is that TMAO-treated p.N432D mutant reaches full maturation, but all the mature receptor undergoes proteolytic cleavage and thus only A-subunit is detected. This may be explained by an increased sensitivity of the TSHR mutant to proteases or because a lower amount of mutant TSHR on the membrane more effectively processed by proteases.

Irrespectively of these considerations, functional assays show that p.N432D mutant is able to bind TSH and transduce intracellular signal when expressed on plasma membrane (Fig. 5 A-C and Table 2). The lack of Gq11/IP3 pathway activity may be explained by the intrinsic differences between Gs and Gq interaction with TSHR. First of all, the Gq11/IP3 pathway is more dependent upon the total amount of cleaved receptor (10) and on TSHR homodimerization abilities (48) and TMAO treated p.N432D has an absolute amount of cleaved receptor present on plasma membrane definitely lower than WT one (Fig. 4 and Suppl. Fig. 2). In addition, interactions between TSHR and Gq are more demanding than the ones with Gs $(4,49)$, and an in silico model predicted that p.N432D mutation severe modifications can affect the interaction with G-protein (21). The treatment with TMAO can either mask these conformational alterations or force the mutant through a more correct conformation that is enough to achieve a partial rescue of Gs interactions and cAMP signaling but is not enough to restore the more demanding interactions with Gq. 
346 These speculations are also supported by the findings on two other discordant mutants, where 347 TMAO treatment more efficiently rescues Gs/cAMP than the Gq11/IP3 signaling (Fig. 5 D-H and 348 Suppl. Fig. 4 B).

349 In conclusion, our work shows that TSHR can be degraded through proteasome or autophagosome 350 pathways depending on specific structural defects. The chaperone TMAO allows TSHR mutants to 351 pass ER quality control, increasing cell surface expression. As for other GPCR-related diseases, 352 TSHR LOF mutations are mainly causing ER retention, as detected by the discrepancy between in 353 silico predictions and in vitro data. As we demonstrated here, retained mutants that are brought to 354 the cell surface are able to effectively transduce intracellular signal. These findings open the 355 possibility of further studies on pharmacological modulation of TSHR expression and functionality 356 in patients with disrupted TSHR signaling. 


\section{Acknowledgments}

358 Grassi ES was partially supported by Fondazione Rusconi PhD scholarship.

359 The work was partially supported by Ricerca Corrente funds of Istituto Auxologico Italiano 360 (EPIPOT; code: 05C002_2010).

361 Grassi ES, Labadi A and Ghiandai V designed and performed the experiments.

362 Vezzoli V and Bonomi M contributed to the experiment planning.

363 LP supervised the experimental work and provided research funds.

364 All authors contributed to the writing and revision of the manuscript.

365

366 Author Disclosure Statement

367 No competing financial interests exist. 


\section{References}

371 1. Persani L, Rurale G, de Filippis T et al. Genetics and management of congenital 372 hypothyroidism. Best Pract Res Clin Endocrinol Metab. 2018;32(4):387-396. 373 doi:10.1016/j.beem.2018.05.002.

2. Persani L, Calebiro D, Cordella D, et al. Genetics and phenomics of hypothyroidism due to TSH resistance. Mol Cell Endocrinol. 2010;322(1-2):72-82. doi:10.1016/j.mce.2010.01.008.

3. Kursawe R, Paschke R. Modulation of TSHR signaling by posttranslational modifications. Trends Endocrinol Metab. 2007;18(5):199-207. doi:10.1016/j.tem.2007.05.002.

4. Kleinau G, Neumann S, Grüters A et al. Novel insights on thyroid-stimulating hormone receptor signal transduction. Endocr Rev. 2013;34(5):691-724. doi:10.1210/er.2012-1072.

5. Siffroi-Fernandez S, Giraud A, Lanet J et al.. Association of the thyrotropin receptor with

6. Costagliola S, Panneels V, Bonomi M, et al. Tyrosine sulfation is required for agonist

7. Bulenger S, Marullo S, Bouvier M. Emerging role of homo- and heterodimerization in Gprotein-coupled receptor biosynthesis and maturation. Trends Pharmacol Sci. 2005;26(3):131-137. doi:10.1016/j.tips.2005.01.004.

8. Bonomi M, Busnelli M, Persani Let al. Structural differences in the hinge region of the glycoprotein hormone receptors: Evidence from the sulfated tyrosine residues. Mol Endocrinol. 2006;20(12):3351-3363. doi:10.1210/me.2005-0521. 
392 9. Rapoport B, McLachlan SM. TSH Receptor Cleavage Into Subunits and Shedding of the A393 Subunit; A Molecular and Clinical Perspective. Endocr Rev. 2016;37(2):114-134. doi:10.1210/er.2015-1098.

395

396

397

398

399

400

401

402

403

404

405

406

407

408

409

410

10. $\mathrm{Vu}$ M-TH, Radu A, Ghinea N. The cleavage of thyroid-stimulating hormone receptor is dependent on cell-cell contacts and regulates the hormonal stimulation of phospholipase c. J Cell Mol Med. 2009;13(8B):2253-2260. doi:10.1111/j.1582-4934.2008.00422.x.

11. Mizrachi D, Segaloff DL. Intracellularly located misfolded glycoprotein hormone receptors associate with different chaperone proteins than their cognate wild-type receptors. Mol Endocrinol. 2004;18(7):1768-1777. doi:10.1210/me.2003-0406.

12. Young B, Wertman J, Dupré DJ. Regulation of GPCR Anterograde Trafficking by Molecular Chaperones and Motifs. Prog Mol Biol Transl Sci. 2015;132:289-305. doi:10.1016/bs.pmbts.2015.02.012.

13. Milligan G. The role of dimerisation in the cellular trafficking of G-protein-coupled receptors. Curr Opin Pharmacol. 2010;10(1):23-29. doi:10.1016/j.coph.2009.09.010.

14. Conn PM, Ulloa-Aguirre A, Ito J at al. G Protein-Coupled Receptor Trafficking in Health and Disease: Lessons Learned to Prepare for Therapeutic Mutant Rescue in Vivo. Pharmacol Rev. 2007;59(3):225-250. doi:10.1124/pr.59.3.2.

15. Newton CL, Whay AM, McArdle CA, et al. Rescue of expression and signaling of human luteinizing hormone $\mathrm{G}$ protein-coupled receptor mutants with an allosterically binding smallmolecule agonist. Proc Natl Acad Sci U S A. 2011;108(17):7172-7176. doi:10.1073/pnas.1015723108.

16. Rivero-Müller A, Chou Y-Y, Ji I, et al. Rescue of defective G protein-coupled receptor function in vivo by intermolecular cooperation. Proc Natl Acad Sci U S A. 
2010;107(5):2319-2324. doi:10.1073/pnas.0906695106.

17. Janovick JA, Pogozheva ID, Mosberg HI et al. Rescue of misrouted GnRHR mutants reveals its constitutive activity. Mol Endocrinol. 2012;26(7):1179-1188. doi:10.1210/me.2012-1089.

18. Sato S, Ward CL, Krouse ME et al. Glycerol reverses the misfolding phenotype of the most common cystic fibrosis mutation. J Biol Chem. 1996;271(2):635-638. http://www.ncbi.nlm.nih.gov/pubmed/8557666. Accessed January 12, 2017.

19. Baskakov I V, Kumar R, Srinivasan G et al. Trimethylamine N-oxide-induced cooperative folding of an intrinsically unfolded transcription-activating fragment of human glucocorticoid receptor. J Biol Chem. 1999;274(16):10693-10696. http://www.ncbi.nlm.nih.gov/pubmed/10196139. Accessed January 12, 2017.

20. Granell S, Mohammad S, Ramanagoudr-Bhojappa R et al. Obesity-Linked Variants of Melanocortin-4 Receptor Are Misfolded in the Endoplasmic Reticulum and Can Be Rescued to the Cell Surface by a Chemical Chaperone. Mol Endocrinol. 2010;24(9):1805-1821. doi:10.1210/me.2010-0071.

21. Lábadi Á, Grassi ES, Gellén B, et al. Loss-of-Function Variants in a Hungarian Cohort Reveal Structural Insights on TSH Receptor Maturation and Signaling. J Clin Endocrinol Metab. 2015;100(7):E1039-45. doi:10.1210/jc.2014-4511.

22. Agretti P, De Marco G, Capodanno A, et al. A fast method to detect cell surface expression of thyrotropin receptor (TSHr): The microchip flow cytometry analysis. Thyroid. 2007;17(9):861-868. doi:10.1089/thy.2007.0114.

23. De Marco G, Agretti P, Camilot M, et al. Functional studies of new TSH receptor (TSHr) mutations identified in patients affected by hypothyroidism or isolated hyperthyrotrophinaemia. Clin Endocrinol (Oxf). 2009;70(2):335-338. doi:10.1111/j.1365- 

2265.2008.03333.x.

24. Costagliola S, Rodien P, Many MC, Ludgate M et al. Genetic immunization against the human thyrotropin receptor causes thyroiditis and allows production of monoclonal antibodies recognizing the native receptor. J Immunol. 1998;160(3):1458-1465. http://www.ncbi.nlm.nih.gov/pubmed/9570567. Accessed October 12, 2016.

25. Costagliola S, Khoo D, Vassart G. Production of bioactive amino-terminal domain of the thyrotropin receptor via insertion in the plasma membrane by a glycosylphosphatidylinositol anchor. FEBS Lett. 1998;436(3):427-433. http://www.ncbi.nlm.nih.gov/pubmed/9801163. Accessed October 12, 2016.

26. Alberti L, Proverbio MC, Costagliola S, et al. A novel germline mutation in the TSH receptor gene causes non-autoimmune autosomal dominant hyperthyroidism. Eur J Endocrinol. 2001;145(3):249-254. http://www.ncbi.nlm.nih.gov/pubmed/11517004. Accessed October $12,2016$.

27. Urizar E, Montanelli L, Loy T, et al. Glycoprotein hormone receptors: link between receptor homodimerization and negative cooperativity. EMBO J. 2005;24(11):1954-1964. doi:10.1038/sj.emboj.7600686.

28. Minich WB, Lenzner C, Morgenthaler NG. Antibodies to TSH-receptor in thyroid autoimmune disease interact with monoclonal antibodies whose epitopes are broadly distributed on the receptor. Clin Exp Immunol. 2004;136(1):129-136. doi:10.1111/j.13652249.2004.02417.x.

29. Lüblinghoff J, Nebel IT, Huth S, et al. The leipzig thyrotropin receptor mutation database: update 2012. Eur Thyroid J. 2012;1(3):209-210. doi:10.1159/000342918.

30. Grassi ES, Vezzoli V, Negri I, et al. SP600125 has a remarkable anticancer potential against 
undifferentiated thyroid cancer through selective action on ROCK and p53 pathways. Oncotarget. 2015;6(34):36383-36399. doi:10.18632/oncotarget.5799.

31. Schindelin J, Arganda-Carreras I, Frise E, et al. Fiji: An open-source platform for biologicalimage analysis. Nat Methods. 2012;9(7):676-682. doi:10.1038/nmeth.2019.

32. Lábadi Á, Grassi ES, Gellén B, et al. Loss-of-function variants in a hungarian cohort reveal structural insights on TSH receptor maturation and signaling. J Clin Endocrinol Metab. 2015;100(7). doi:10.1210/jc.2014-4511.

33. Houck SA, Ren HY, Madden VJ, et al. Quality control autophagy degrades soluble ERADresistant conformers of the misfolded membrane protein GnRHR. Mol Cell. 2014;54(1):166179. doi:10.1016/j.molcel.2014.02.025.

34. Lu M, Echeverri F, Moyer BD. Endoplasmic reticulum retention, degradation, and aggregation of olfactory G-protein coupled receptors. Traffic. 2003;4(6):416-433. http://www.ncbi.nlm.nih.gov/pubmed/12753650. Accessed October 12, 2016.

35. Saliba RS, Munro PMG, Luthert PJ at al. The cellular fate of mutant rhodopsin: quality control, degradation and aggresome formation. J Cell Sci. 2002;115(14).

36. D'Agostino M, Crespi A, Polishchuk E, et al. ER reorganization is remarkably induced in COS-7 cells accumulating transmembrane protein receptors not competent for export from the endoplasmic reticulum. J Membr Biol. 2014;247(11):1149-1159. doi:10.1007/s00232014-9710-8.

37. Cook LB, Zhu C-C, Hinkle PM. Thyrotropin-Releasing Hormone Receptor Processing: Role of Ubiquitination and Proteasomal Degradation. Mol Endocrinol. 2003;17(9):1777-1791. doi:10.1210/me.2003-0073. 
483 38. Petaja-Repo UE, Hogue M, Laperriere A et al. Newly Synthesized Human Opioid Receptors Retained in the Endoplasmic Reticulum Are Retrotranslocated to the Cytosol, Deglycosylated, Ubiquitinated, and Degraded by the Proteasome. J Biol Chem. 2001;276(6):4416-4423. doi:10.1074/jbc.M007151200.

39. Lahuna O, Quellari M, Achard C, et al. Thyrotropin receptor trafficking relies on the hScribbetaPIX-GIT1-ARF6 pathway. EMBO J. 2005;24(7):1364-1374. doi:10.1038/sj.emboj.7600616.

40. Ho SC, Van Sande J, Lefort A et al. Effects of mutations involving the highly conserved S281HCC motif in the extracellular domain of the thyrotropin (TSH) receptor on TSH binding and constitutive activity. Endocrinology. 2001;142(7):2760-2767. doi:10.1210/endo.142.7.8246.

41. Ding WX, Y in XM. Sorting, recognition and activation of the misfolded protein degradation pathways through macroautophagy and the proteasome. Autophagy. 2008;4(2):141-150. doi:10.4161/auto.5190.

42. Siffroi-Fernandez S, Costagliola S, Paumel S, Giraud A et al. Role of complex asparaginelinked oligosaccharides in the expression of a functional thyrotropin receptor. Biochem J. 2001;354(Pt 2):331-336. http://www.ncbi.nlm.nih.gov/pubmed/11171111. Accessed October $12,2016$.

43. Sura-Trueba S, Aumas C, Carre A, et al. An inactivating mutation within the first extracellular loop of the thyrotropin receptor impedes normal posttranslational maturation of the extracellular domain. Endocrinology. 2009;150(2):1043-1050. doi:10.1210/en.20081145.

44. Chen DN, Ma YT, Liu H et al. Functional rescue of Kallmann syndrome-associated 
prokineticin receptor 2 (PKR2) mutants deficient in trafficking. J Biol Chem. 2014;289(22):15518-15526. doi:10.1074/jbc.M114.556381.

45. Robben JH, Sze M, Knoers NVAM et al. Rescue of vasopressin V2 receptor mutants by chemical chaperones: Specificity and mechanism. Mol Biol Cell. 2006;17(1):379-386. doi:10.1091/mbc.E05-06-0579.

46. Nagayama $\mathrm{Y}$, Nishihara E, Namba $\mathrm{H}$ et al. Identification of the sites of asparagine-linked glycosylation on the human thyrotropin receptor and studies on their role in receptor function and expression. J Pharmacol Exp Ther. 2000;295(1):404-409. http://www.ncbi.nlm.nih.gov/pubmed/10992007. Accessed October 12, 2016.

47. Nagayama $\mathrm{Y}$, Namba $\mathrm{H}$, Yokoyama $\mathrm{N}$ et al. Role of asparagine-linked oligosaccharides in protein folding, membrane targeting, and thyrotropin and autoantibody binding of the human thyrotropin receptor. J Biol Chem. 1998;273(50):33423-33428. http://www.ncbi.nlm.nih.gov/pubmed/9837919. Accessed October 12, 2016.

48. Allen MD, Neumann S, Gershengorn MC. Occupancy of both sites on the thyrotropin (TSH) receptor dimer is necessary for phosphoinositide signaling. FASEB J. 2011;25(10):36873694. doi:10.1096/fj.11-188961.

49. Kleinau G, Jaeschke H, Worth CL, et al. Principles and Determinants of G-Protein Coupling by the Rhodopsin-Like Thyrotropin Receptor. Hansen IA, ed. PLoS One. 2010;5(3):e9745. doi:10.1371/journal.pone.0009745. 
1 Table 1: in vitro and in silico functionality concordance of TSHR variant with different subcellular localization. Distribution of TSHR variants from in vitro data and in silico predictions concordance of function in relation to subcellular localization. For 55 different variants data about

4 in vitro subcellular localization and functionality were obtained through literature review. In silico

5 prediction were obtained with 6 different online tools and each variant was then assigned to one of

6 the four groups: membrane localization with in vitro and in silico concordance on functionality,

7 membrane localization with in vitro and in silico discordance on functionality, intracellular

8 retainment with in vitro and in silico concordance on functionality, intracellular retainment with in

9 vitro and in silico discordance on functionality.

\begin{tabular}{|l|l|c|c|c|}
\cline { 3 - 5 } \multicolumn{2}{c|}{} & \multicolumn{2}{c|}{ LOCALIZATION } & \multicolumn{1}{c}{} \\
\cline { 3 - 5 } \multicolumn{2}{c|}{} & RETAINED & MEMBRANE & TOTAL \\
\hline \multirow{3}{*}{ PREDICTION } & CONCORDANT & 12 & 24 & 36 \\
\cline { 2 - 5 } & DISCORDANT & 12 & 7 & 19 \\
\hline & TOTAL & 24 & 31 & 55 \\
\hline
\end{tabular}


2 Table 2: membrane expression and functional parameters of the LOF TSHR variants. The

3 table summarize the main characteristics of the LOF THSR variants. Membrane expression was

4 examined with flow cytometry as in figure 4C and 4E. Maximal stimulation and EC50 were

5 obtained from experiment as in Figure 5. Values are expressed as mean \pm SD.

6 Statistical analysis: statistical significance was determined with One-Way ANOVA. * $\mathrm{p}<0.05, * *$

$7 \mathrm{p}<0.01, * * * \mathrm{p}<0.001$ vs. WT TSHR, $\S \S \S \mathrm{p}<0.001$ vs. the respective untreated TSHR variant.

\begin{tabular}{|l|l|l|l|l|l|}
\hline & Membrane & Membrane & IP1 & cAMP & cAMP \\
& expression & expression & Emax(\% WT) & Emax & EC50 \\
& $\mathbf{( 3 G 4 )}$ & $\mathbf{( B A 8 )}$ & & $(\mathbf{\%}$ WT) & (U/L) \\
\hline WT & $100.00 \pm 1.09$ & $100.00 \pm 0.61$ & $100.00 \pm 10.41$ & $100.00 \pm 1.80$ & $0.10 \pm 0.04$ \\
\hline $\begin{array}{l}\text { WT }+ \\
\text { TMAO }\end{array}$ & $102.90 \pm 1.31$ & $97.17 \pm 2.75$ & $115.10 \pm 13.61$ & $101.00 \pm 6.33$ & $0.04 \pm 0.05$ \\
\hline p.N432D & $\begin{array}{l}1.75 \pm 2.06 \\
* * *\end{array}$ & $\begin{array}{l}0.31 \pm 0.55 \\
* * *\end{array}$ & $\begin{array}{l}9.12 \pm 2.08 \\
* * *\end{array}$ & $\begin{array}{l}1.53 \pm 0.01 \\
* * *\end{array}$ & - \\
\hline $\begin{array}{l}\text { p.N342D }+ \\
\text { TMAO }\end{array}$ & $\begin{array}{l}51.03 \pm 9.19 \\
* * * \S \S \S\end{array}$ & $\begin{array}{l}77.3 \pm 4.021 \\
* * * \S \S \S\end{array}$ & $\begin{array}{l}10.36 \pm 1.74 \\
* * *\end{array}$ & $\begin{array}{l}76.61 \pm 3.50 \\
* * * \S \S \S\end{array}$ & $\begin{array}{l}0.75 \pm 0.09 \\
* * *\end{array}$ \\
\hline p.P449L & $\begin{array}{l}128.8 \pm 5.37 \\
* * *\end{array}$ & $\begin{array}{l}118.3 \pm 4.64 \\
* *\end{array}$ & $\begin{array}{l}30.96 \pm 6.96 \\
* * *\end{array}$ & $\begin{array}{l}67.95 \pm 1.26 \\
* * *\end{array}$ & $\begin{array}{l}0.62 \pm 0.07 \\
* * *\end{array}$ \\
\hline $\begin{array}{l}\text { p.P449L }+ \\
\text { TMAO }\end{array}$ & $\begin{array}{l}133.80 \pm \\
4.99 * * *\end{array}$ & $\begin{array}{l}109.1 \pm 5.51 \\
*\end{array}$ & $\begin{array}{l}22.25 \pm 6.21 \\
* * *\end{array}$ & $\begin{array}{l}67.24 \pm 2.98 \\
* * *\end{array}$ & $\begin{array}{l}1.09 \pm 0.04 \\
* * * \S \S\end{array}$ \\
\hline EMPTY & $\begin{array}{l}0.36 \pm 4.40 \\
* * *\end{array}$ & $\begin{array}{l}0.41 \pm 0.40 \\
* * *\end{array}$ & $\begin{array}{l}6.16 \pm 1.98 \\
* * *\end{array}$ & $\begin{array}{l}2.85 \pm 2.23 \\
* * *\end{array}$ & - \\
\hline $\begin{array}{l}\text { EMPTY }+ \\
\text { TMAO }\end{array}$ & $\begin{array}{l}1.06 \pm 2.06 \\
* * *\end{array}$ & $\begin{array}{l}0.95 \pm 0.87 \\
* * *\end{array}$ & $\begin{array}{l}7.17 \pm 7.40 \\
* * *\end{array}$ & $\begin{array}{l}2.88 \pm 2.25 \\
* * *\end{array}$ & - \\
\hline
\end{tabular}


Figure legends.

\section{Figure 1: TSHR maturation and the hypothesized degradation pathways.}

THSR is constituted of a seven-transmembrane alpha helix B-subunit (green) and an extracellular A-subunit (purple). It is synthesized in the endoplasmic reticulum as a full length unglycosylated protein (A, immature form). The acquisition of mannose-type carbohydrates (B, high-mannose form) permits the interactions with molecular chaperones like calnexin and calreticulin, thus facilitating protein folding and is required for receptor homodimerization, allowing passage through ER quality control system and translocation to cis-Golgi $(\mathrm{F})$. The TSHR maturation continues (C) as it passes to the trans-Golgi where it acquires the complex-type carbohydrates that characterize the mature form of the protein (D, complex carbohydrates form) that is expressed on the cell surface. The majority of mature TSHR present on cell membrane is cleaved with loss of a small aminoacidic sequence of variable size, named peptide $\mathrm{C}$. The receptor is thus finally composed of a transmembrane B-subunit linked by disulfide bonds to the extracellular A-subunit that can have slightly different dimensions depending on the cleavage sites and carries all the carbohydrate side chains (E, grey discontinued line indicates that only A-subunit is shown in western blot image).

The TSHR can be degraded through different systems. The misfolded receptors not able to proceed through the endoplasmic reticulum may be directed toward the proteasome $(\mathrm{G})$ or the endolysosome (H) systems, depending on the nature of the alterations. Receptors not able to proceed through maturation in the Golgi can be retrotranslocated to the ER (F) for another round of control or directed toward degradation (I). The turnover of normal membrane TSHR also occurs through the endolysosme system after receptor endocytosis (I). 
Figure 2: p.N432D mutant is retained in the ER and lysosomes in different aggregates.

A: representative images of WT TSHR, p.P449L mutant and empty vector transfected cells stained with $3 \mathrm{G} 4$ and $\mathrm{BA} 8$ antibodies.

B: representative images of the different morphological presentations of p.N432D mutant after antiTSHR 3 G4 or anti-TSHR BA8 antibodies staining. For BA8 antibody: PS, perinuclear signal; SA, small intracellular aggregates; MA, macroaggregates; MM, mixed morphology, concomitant presence of PS, SA and/or MA detected with BA8 antibody. 3G4 antibody detected a constant mix of perinuclear signal and small aggregates.

$\mathrm{C}$ : quantification of the relative frequencies of the different $\mathrm{p} . \mathrm{N} 432 \mathrm{D}$ patterns detected with BA8 antibody as in Fig. 2B. PS, perinuclear signal; SA, small intracellular aggregates; MA, macroaggregates; MM, mixed morphology, concomitant presence of PS, SA and/or MA detected with BA8 antibody.

D: representative images of colocalization experiment showing endoplasmic reticulum (ER, red) and N432D mutant (green) stained with either BA8 or 3G4 antibodies.

\section{E: analysis of Pearson's coefficient for colocalization. The graph represents the averages of the} Pearsons' coefficients for colocalization detected for N432D mutant stained with either BA8 or 3G4 antibodies and Endoplasmic Reticulum.

F: representative images of colocalization experiments showing late endosome/lysosomes (LYSO, red) and N432D mutant (green) stained with either BA8 or 3G4 antibodies.
G: analysis of Pearson's coefficient for colocalization. The graph represents the averages of the

Pearsons' coefficients for colocalization detected for N432D mutant stained with either BA8 or 3G4 antibodies and late endosome/lysosomes. 
Statistical analysis: $C \mathrm{n}=14$ (2018 cells analyzed), $\mathrm{E} n=12$ ( 248 cells analyzed), $\mathrm{G} n=6$ (110 cells analyzed). Statistical significance was determined with One-Way ANOVA in C and t-test with Welch's correction in $\mathrm{E}$ and $\mathrm{G} .{ }^{*} \mathrm{p}<0.05$ and $* * * \mathrm{p}<0.001$ as indicated.

Figure 3: WT and mutant TSHRs are degraded through different pathways.

A: representative western blot images of TSHR expression and maturation after treatment with 20 $\mathrm{mM} \mathrm{NH}_{4} \mathrm{Cl}, 10 \mu \mathrm{M}$ MG132 and a combination of the two inhibitors. TSHR was stained with 28.1 antibody, GFP was used as transfection efficiency control and actin was used as loading control.

B: densitometric quantification of western blot experiments showing complex carbohydrates, high mannose and A subunit forms of TSHR after treatment with NH4Cl, MG132 and a combination of the two inhibitors.

C: representative images and relative quantification of confocal microscopy experiments showing anti-TSHR BA8 antibody staining of p.N432D mutant after treatment with $\mathrm{NH}_{4} \mathrm{Cl}, \mathrm{MG} 132$ and a combination of the two inhibitors. For each treatment, the signal pattern with bigger fold change increase in respect to control is shown. White, perinuclear signal (PS); light grey, small intracellular aggregates (SA); intermediate grey, macroaggregates (MA); dark grey, mixed morphology (MM).

D: representative western blot images of TSHR expression and maturation after treatment with 10 mM LiCl. TSHR was stained with 28.1 antibody, GFP was used as transfection efficiency control and actin was used as loading control.

E: densitometric quantification of western blot experiments showing complex carbohydrates, high mannose and A subunit forms of TSHR after treatment with $\mathrm{LiCl}$.

Statistical analysis: $B$ n=4, C n=14, E n=3. Statistical significance was determined with One-Way ANOVA (non-parametric Kruskal-Wallis H test) followed by Dunn's post hoc test. 
$69{ }^{*} \mathrm{p}<0.05, * * \mathrm{p}<0.01$ and $* * * \mathrm{p}<0.001$ as indicated.

70

71 
Figure 4: TMAO restores p.N432D mutant trafficking and membrane expression.

A: representative images of western blotting experiments showing the expression and maturation of the TSHR variants without and after treatment with TMAO. TSHR was stained with 28.1 antibody, GFP was used as transfection efficiency control and actin was used as loading control.

B: densitometric quantification of western blot experiments showing complex carbohydrates, high mannose and A subunit forms of TSHR without and after TMAO treatment.

C: representative flow cytometric histograms showing BA8 antibody signal in unpermeabilized cells with or without TMAO treatment. The R-1 markers indicate cells expressing TSHR and were used to quantitate receptor expression based on the mean fluorescence intensity. Untreated samples, light blue area; TMAO-treated samples, red area; overlapping area, green.

D: mean fluorescence intensity quantification of the TSHR variants expression on cell membrane without or after TMAO treatment, with 3G4 antibody labeling. Values are expressed as percentage of untreated WT.

E: representative flow cytometric histograms showing 3G4 antibody signal in unpermeabilized cells with or without TMAO treatment. The R-1 markers indicate cells expressing TSHR and were used to quantitate receptor expression based on the mean fluorescence intensity. Untreated samples, light blue area; TMAO-treated samples, red area; overlapping area, green.

F: mean fluorescence intensity quantification of the TSHR variants expression on cell membrane without or after TMAO treatment, with 3G4 antibody labeling. Values are expressed as percentage of untreated WT.

G: representative images of confocal microscopy experiments performed with BA8 staining, showing TSHR variants in normal conditions and after TMAO treatment. TSHR, green staining, nuclei, blue DAPI staining. 
95 Statistical analysis: $B \mathrm{n}=3, \mathrm{D} n=6, \mathrm{~F} n=6$. Statistical significance was determined with One-Way

96 ANOVA followed by Dunns (D,F) or Bonferroni (B) post hoc test. .

$97 * \mathrm{p}<0.05, * * \mathrm{p}<0.01, * * * \mathrm{p}<0.001$ in respect to untreated TSHR WT.

98

99 
Figure 5: TMAO treatment unveiled partial functionality of N432D and other known retained mutants.

A: Gq11/IP3 pathway activity after maximal dose stimulation of TSHR WT, p.N432D and p.P449L variants upon normal conditions and after TMAO treatment, measured as IP1 accumulation and expressed as percentage of stimulated WT activity.

B: Gs/cAMP pathway activity after maximal dose stimulation of TSHR WT, p.N432D and p.P449L variants upon normal conditions and after TMAO treatment, measured as cAMP reporter luciferase activity and expressed as percentage of stimulated WT activity.
C: dose-response curves for Gs/cAMP signaling of TSHR WT, p.N432D and p.P449L variants after TMAO treatment. Each variants' curve is expressed as a percentage of its own Emax.

D: representative images of western blotting experiments showing the expression and maturation of the TSHR variants without and after treatment with TMAO. TSHR was stained with 28.1 antibody, actin was used as loading control.

F: Gq11/IP3 pathway activity after maximal dose stimulation of TSHR WT, p.E34K and p.R46P variants upon normal conditions and after TMAO treatment, measured as IP1 accumulation and expressed as percentage of stimulated WT activity.

G: Gs/cAMP pathway activity after maximal dose stimulation of TSHR WT, p.E34K and p.R46P variants upon normal conditions and after TMAO treatment, measured as cAMP reporter luciferase activity and expressed as percentage of stimulated WT activity.

H: dose-response curves for Gs/cAMP signaling of TSHR WT, p.E34K and p.R46P variants after TMAO treatment. Each variants' curve is expressed as a percentage of its own Emax. 
121 Statistical analysis: A, B, C n=8, E, F, G, H n=3. Statistical significance was determined with One122 Way ANOVA followed by Bonferroni's post hoc test (A, B, C) or Kruskal-Wallis H test followed 123 by Dunn's post hoc test (E, F, G).

$124 * \mathrm{p}<0.05, * * \mathrm{p}<0.01, * * * \mathrm{p}<0.001$ in respect to TMAO untreated TSHR WT or as indicated.

125

126

127

128 


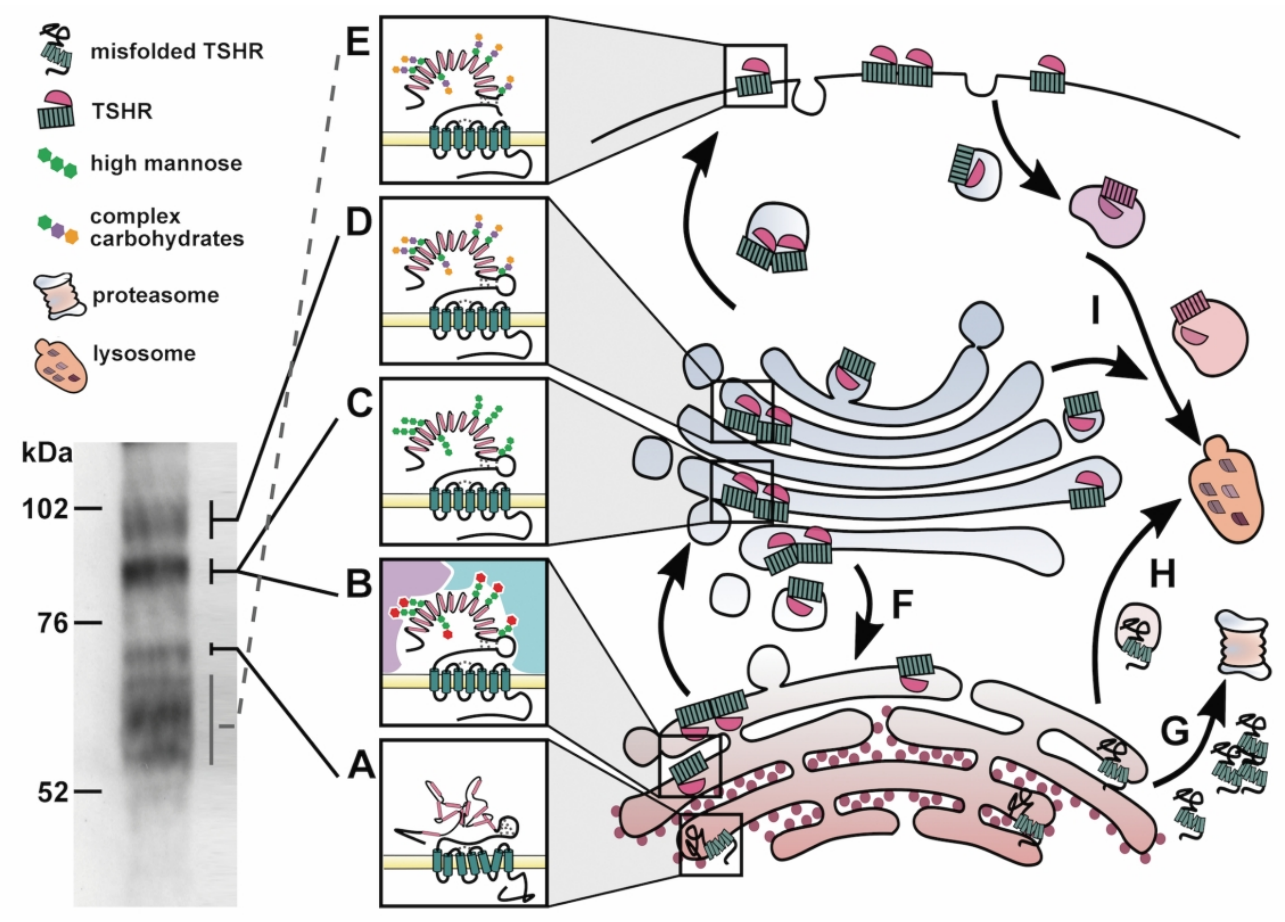

Figure 1: TSHR maturation and the hypothesized degradation pathways.

THSR is constituted of a seven-transmembrane alpha helix B-subunit (green) and an extracellular A-subunit (purple). It is synthesized in the endoplasmic reticulum as a full length unglycosylated protein ( $A$, immature form). The acquisition of mannose-type carbohydrates ( $B$, high-mannose form) permits the interactions with molecular chaperones like calnexin and calreticulin, thus facilitating protein folding and is required for receptor homodimerization, allowing passage through ER quality control system and translocation to cisGolgi (F). The TSHR maturation continues (C) as it passes to the trans-Golgi where it acquires the complextype carbohydrates that characterize the mature form of the protein ( $D$, complex carbohydrates form) that is expressed on the cell surface. The majority of mature TSHR present on cell membrane is cleaved with loss of a small aminoacidic sequence of variable size, named peptide $C$. The receptor is thus finally composed of a transmembrane B-subunit linked by disulfide bonds to the extracellular A-subunit that can have slightly different dimensions depending on the cleavage sites and carries all the carbohydrate side chains ( $E$, grey discontinued line indicates that only A-subunit is shown in western blot image).

The TSHR can be degraded through different systems. The misfolded receptors not able to proceed through the endoplasmic reticulum may be directed toward the proteasome $(G)$ or the endolysosome $(H)$ systems, depending on the nature of the alterations. Receptors not able to proceed through maturation in the Golgi can be retrotranslocated to the ER (F) for another round of control or directed toward degradation (I). The turnover of normal membrane TSHR also occurs through the endolysosme system after receptor endocytosis 
A
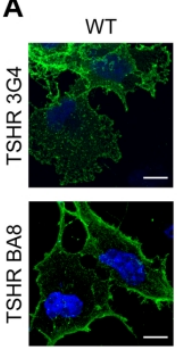

B


P449L


C
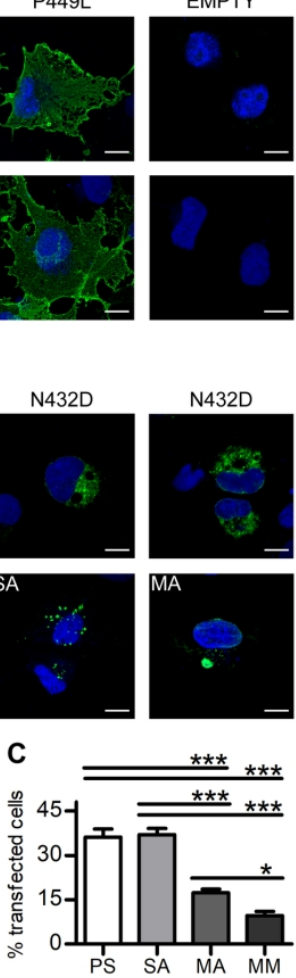

$\mathrm{N} 432 \mathrm{D}$

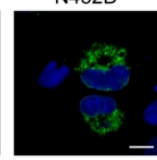

MA

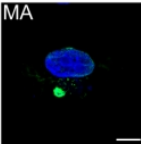

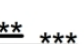

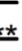

D
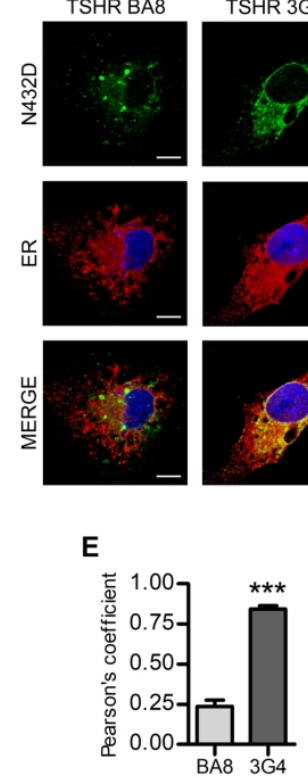

F

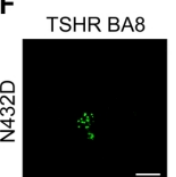

TSHR 3G4


G

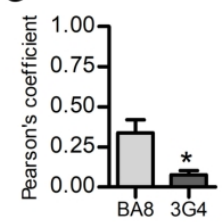

Figure 2: p.N432D mutant is retained in the ER and lysosomes in different aggregates.

A: representative images of WT TSHR, p.P449L mutant and empty vector transfected cells stained with $3 G 4$ and BA8 antibodies.

B: representative images of the different morphological presentations of p.N432D mutant after anti-TSHR $3 G 4$ or anti-TSHR BA8 antibodies staining. For BA8 antibody: PS, perinuclear signal; SA, small intracellular aggregates; MA, macroaggregates; MM, mixed morphology, concomitant presence of PS, SA and/or MA detected with BA8 antibody. 3G4 antibody detected a constant mix of perinuclear signal and small aggregates.

C: quantification of the relative frequencies of the different p.N432D patterns detected with BA8 antibody as in Fig. 2B. PS, perinuclear signal; SA, small intracellular aggregates; MA, macroaggregates; MM, mixed morphology, concomitant presence of PS, SA and/or MA detected with BA8 antibody.

$D$ : representative images of colocalization experiment showing endoplasmic reticulum (ER, red) and N432D mutant (green) stained with either BA8 or 3 G4 antibodies.

E: analysis of Pearson's coefficient for colocalization. The graph represents the averages of the Pearsons' coefficients for colocalization detected for N432D mutant stained with either BA8 or 3G4 antibodies and Endoplasmic Reticulum.

F: representative images of colocalization experiments showing late endosome/lysosomes (LYSO, red) and N432D mutant (green) stained with either BA8 or $3 G 4$ antibodies.

G: analysis of Pearson's coefficient for colocalization. The graph represents the averages of the Pearsons' coefficients for colocalization detected for N432D mutant stained with either BA8 or 3G4 antibodies and late endosome/lysosomes.

Statistical analysis: $C n=14$ (2018 cells analyzed), $E n=12$ ( 248 cells analyzed), $G n=6$ ( 110 cells analyzed). Statistical significance was determined with One-Way ANOVA in C and t-test with Welch's correction in E and G. * $\mathrm{p}<0.05$ and $* * * \mathrm{p}<0.001$ as indicated. 

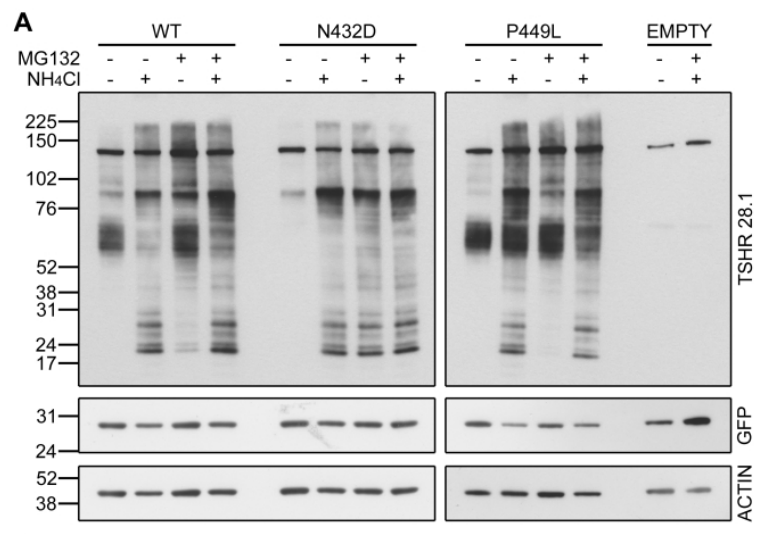

D WT N432D P449L EMPTY

B
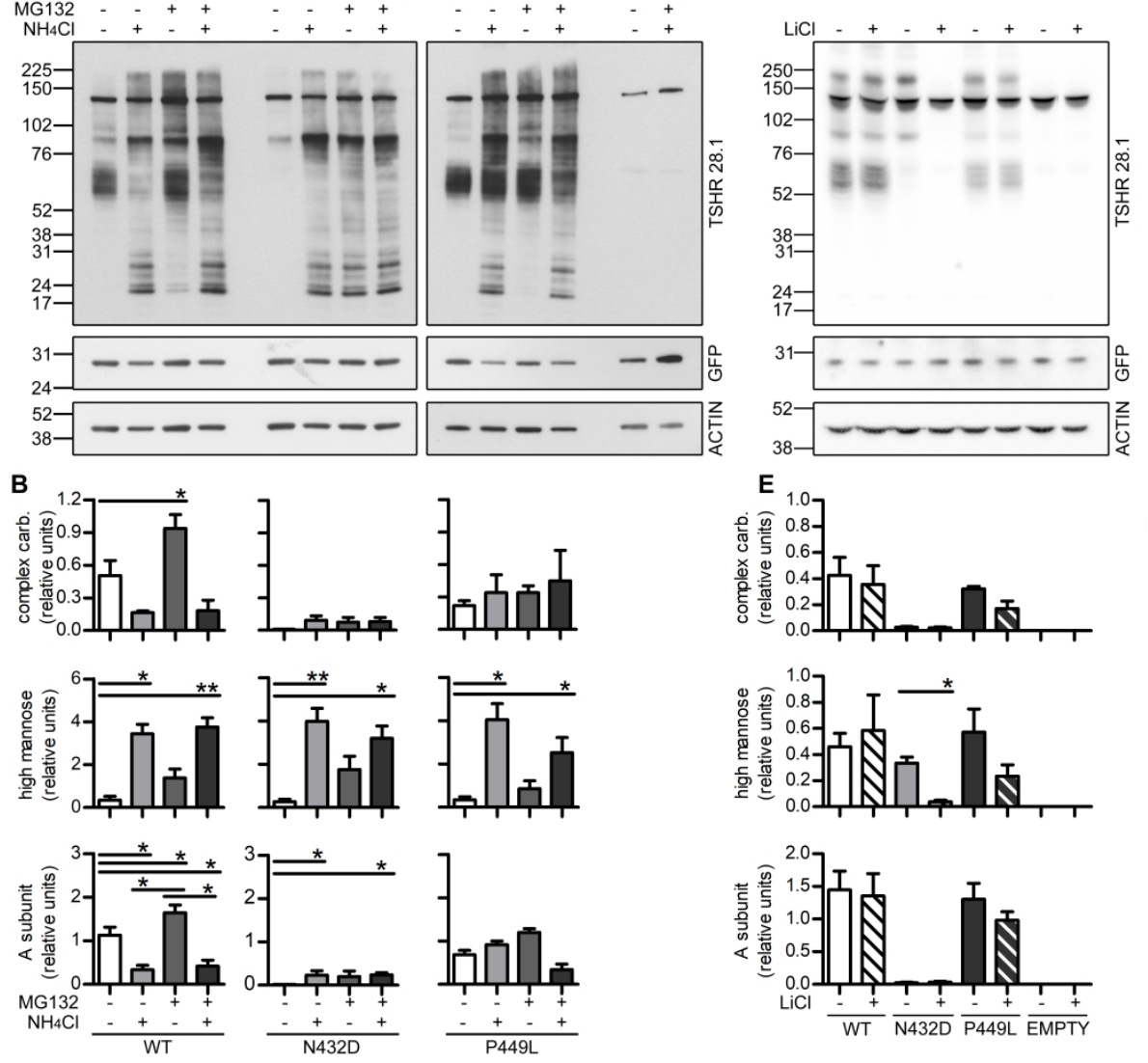

C
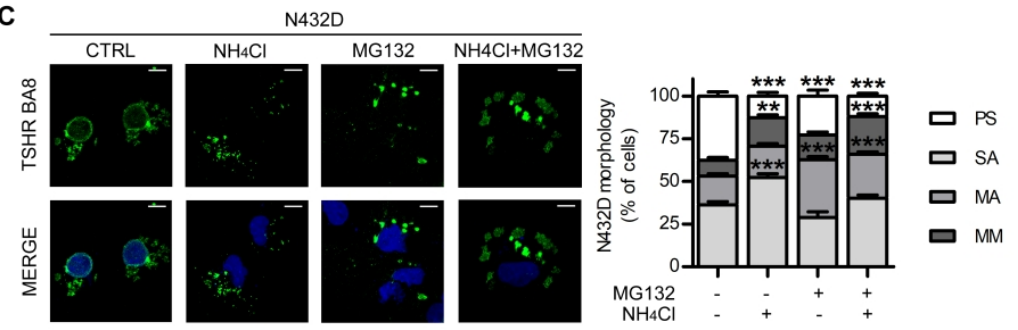

Figure 3: WT and mutant TSHRs are degraded through different pathways.

A: representative western blot images of TSHR expression and maturation after treatment with $20 \mathrm{mM}$ $\mathrm{NH} 4 \mathrm{Cl}, 10 \mu \mathrm{M} \mathrm{MG} 132$ and a combination of the two inhibitors. TSHR was stained with 28.1 antibody, GFP was used as transfection efficiency control and actin was used as loading control.

$B$ : densitometric quantification of western blot experiments showing complex carbohydrates, high mannose and A subunit forms of TSHR after treatment with $\mathrm{NH} 4 \mathrm{Cl}, \mathrm{MG} 132$ and a combination of the two inhibitors.

$C$ : representative images and relative quantification of confocal microscopy experiments showing anti-TSHR BA8 antibody staining of p.N432D mutant after treatment with $\mathrm{NH} 4 \mathrm{Cl}, \mathrm{MG} 132$ and a combination of the two inhibitors. For each treatment, the signal pattern with bigger fold change increase in respect to control is shown. White, perinuclear signal (PS); light grey, small intracellular aggregates (SA); intermediate grey, macroaggregates (MA); dark grey, mixed morphology (MM).

D: representative western blot images of TSHR expression and maturation after treatment with XX mM LiCl. TSHR was stained with 28.1 antibody, GFP was used as transfection efficiency control and actin was used as loading control. 
E: densitometric quantification of western blot experiments showing complex carbohydrates, high mannose and A subunit forms of TSHR after treatment with $\mathrm{LiCl}$.

Statistical analysis: $B n=4, C n=14, E n=3$. Statistical significance was determined with One-Way ANOVA (non-parametric Kruskal-Wallis H test) followed by Dunn's post hoc test. $* \mathrm{p}<0.05, * * \mathrm{p}<0.01$ and $* * * \mathrm{p}<0.001$ as indicated. 
A
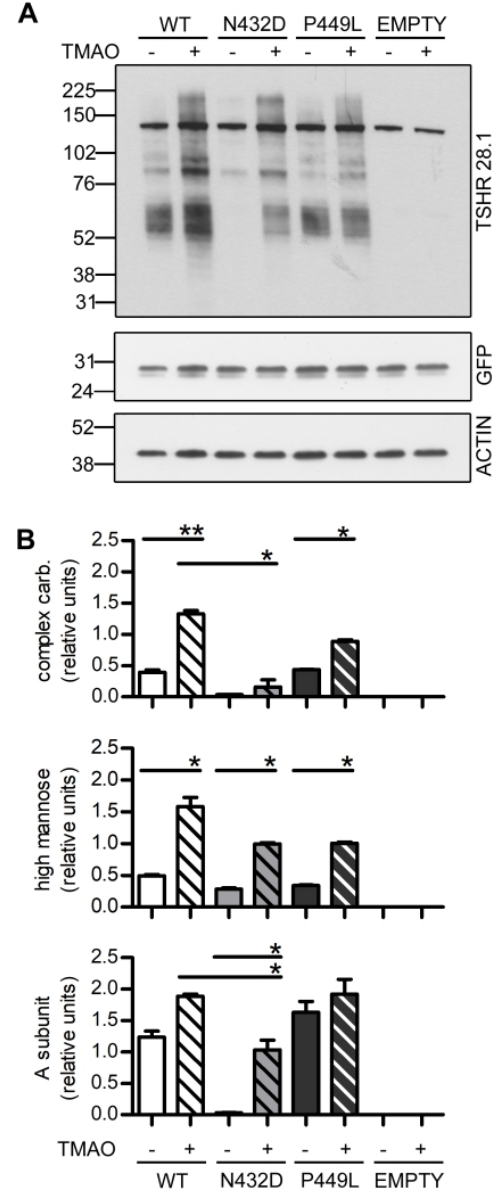

C

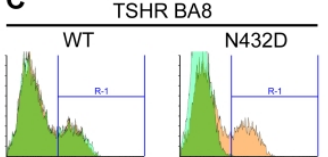

P449L

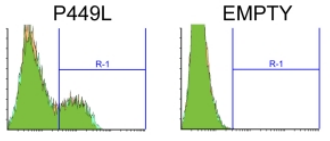

D

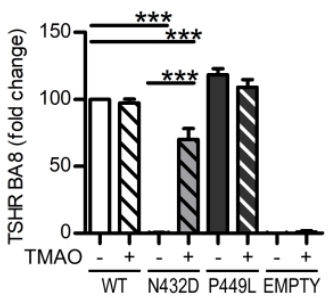

G
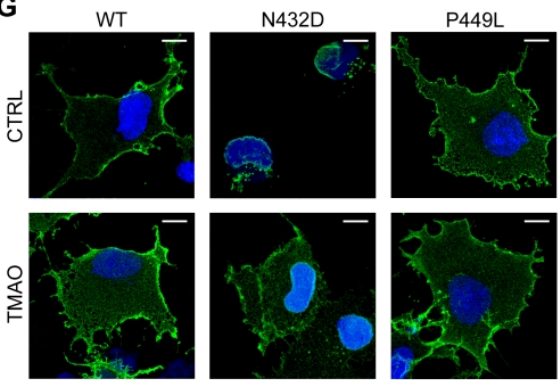

E

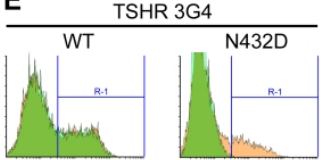

P449L

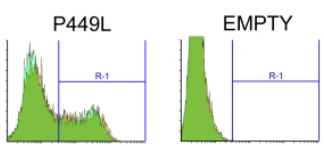

$\mathbf{F}$

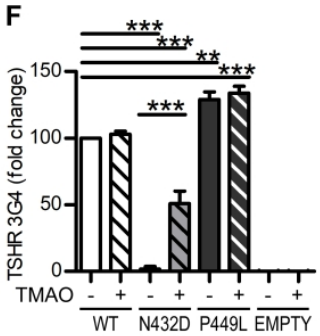

EMPTY

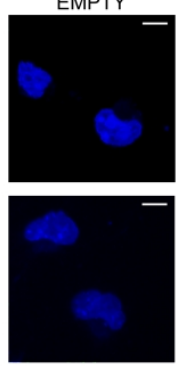

Figure 4: TMAO restores p.N432D mutant trafficking and membrane expression.A: representative images of western blotting experiments showing the expression and maturation of the TSHR variants without and after treatment with TMAO. TSHR was stained with 28.1 antibody, GFP was used as transfection efficiency control and actin was used as loading control. B: densitometric quantification of western blot experiments showing complex carbohydrates, high mannose and A subunit forms of TSHR without and after TMAO treatment. C: representative flow cytometric histograms showing BA8 antibody signal in unpermeabilized cells with or without TMAO treatment. The R-1 markers indicate cells expressing TSHR and were used to quantitate receptor expression based on the mean fluorescence intensity. Untreated samples, light blue area; TMAOtreated samples, red area; overlapping area, green.D: mean fluorescence intensity quantification of the TSHR variants expression on cell membrane without or after TMAO treatment, with 3 G4 antibody labeling. Values are expressed as percentage of untreated WT.E: representative flow cytometric histograms showing $3 G 4$ antibody signal in unpermeabilized cells with or without TMAO treatment. The R-1 markers indicate cells expressing TSHR and were used to quantitate receptor expression based on the mean fluorescence intensity.

Untreated samples, light blue area; TMAO-treated samples, red area; overlapping area, green.F: mean

fluorescence intensity quantification of the TSHR variants expression on cell membrane without or after TMAO treatment, with $3 \mathrm{G} 4$ antibody labeling. Values are expressed as percentage of untreated WT.G: representative images of confocal microscopy experiments performed with BA8 staining, showing TSHR variants in normal conditions and after TMAO treatment. TSHR, green staining, nuclei, blue DAPI staining.Statistical analysis: $B n=3, D n=6, F n=6$. Statistical significance was determined with One-Way ANOVA followed by Dunns $(\mathrm{D}, \mathrm{F})$ or Bonferroni $(B)$ post hoc test. .*p<0.05, $* * p<0.01, * * * p<0.001$ in respect to untreated TSHR WT. 
A



B

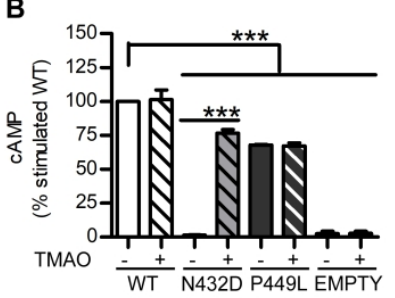

C

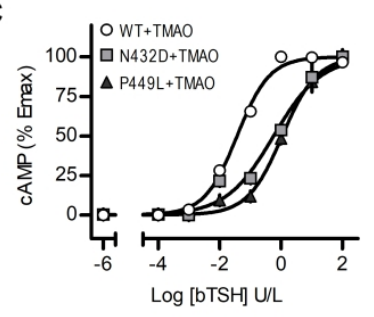

D

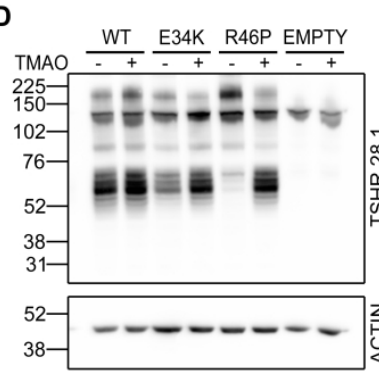

E
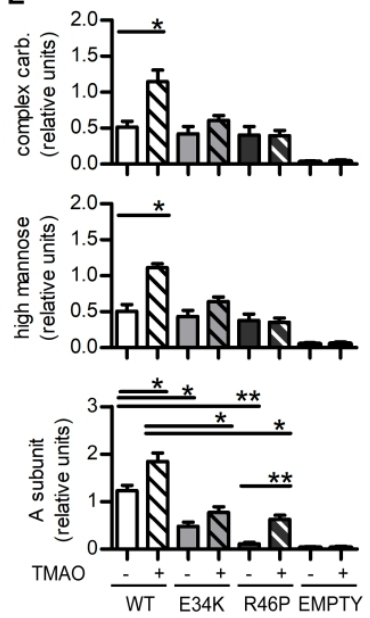

$\mathbf{F}$

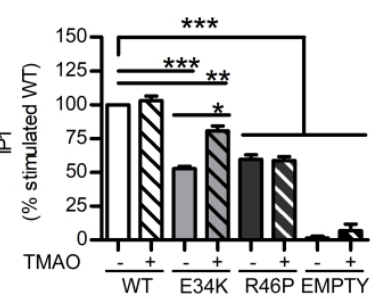

G

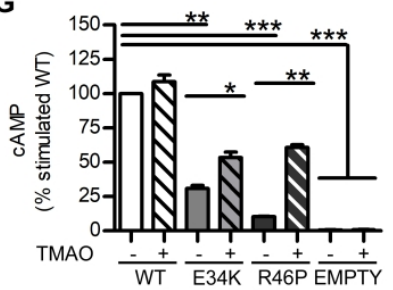

H



Figure 5: TMAO treatment unveiled partial functionality of N432D and other known retained mutants. A: Gq11/IP3 pathway activity after maximal dose stimulation of TSHR WT, p.N432D and p.P449L variants upon normal conditions and after TMAO treatment, measured as IP1 accumulation and expressed as percentage of stimulated WT activity.

B: Gs/cAMP pathway activity after maximal dose stimulation of TSHR WT, p.N432D and p.P449L variants upon normal conditions and after TMAO treatment, measured as CAMP reporter luciferase activity and expressed as percentage of stimulated WT activity.

C: dose-response curves for Gs/cAMP signaling of TSHR WT, p.N432D and p.P449L variants after TMAO treatment. Each variants' curve is expressed as a percentage of its own Emax.

D: representative images of western blotting experiments showing the expression and maturation of the TSHR variants without and after treatment with TMAO. TSHR was stained with 28.1 antibody, actin was used as loading control.

F: Gq11/IP3 pathway activity after maximal dose stimulation of TSHR WT, p.E34K and p.R46P variants upon normal conditions and after TMAO treatment, measured as IP1 accumulation and expressed as percentage of stimulated WT activity.

G: Gs/cAMP pathway activity after maximal dose stimulation of TSHR WT, p.E34K and p.R46P variants upon normal conditions and after TMAO treatment, measured as CAMP reporter luciferase activity and expressed as percentage of stimulated WT activity.

$\mathrm{H}$ : dose-response curves for Gs/cAMP signaling of TSHR WT, p.E34K and p.R46P variants after TMAO treatment. Each variants' curve is expressed as a percentage of its own Emax.

Statistical analysis: $A, B, C n=8, E, F, G, H n=3$. Statistical significance was determined with One-Way ANOVA followed by Bonferroni's post hoc test $(A, B, C)$ or Kruskal-Wallis H test followed by Dunn's post hoc test $(E, F, G)$.

$* \mathrm{p}<0.05, * * \mathrm{p}<0.01, * * * \mathrm{p}<0.001$ in respect to TMAO untreated TSHR WT or as indicated. 


\section{Supplementary Methods}

\section{Chemicals}

Cell culture reagents, ProLong Gold Antifade Reagent with DAPI, LysoTracker Red DND-99, ERTracker Green, Alexa-Fluor conjugated and HRP conjugated secondary antibodies, Restore Western Blot Stripping reagent were purchased from Thermo Fisher. Purified Mouse Anti-Actin Ab-5 was purchased from BD Biosciences. Anti TSHR antibodies BA8 (Cat\# SC_BA8, RRID:AB_2716681), 3G4 (Cat\# SC_3G4, RRID:AB_2716682) and 28.1(Cat\# SC_28.1, RRID:AB_2716683)were described elsewhere (1-5) and were a kind gift from Dr S. Costagliola (IRIBHM, ULB, Brussels). Anti E-Cadherin antibody war purchased from Abcam, anti VDAC was purchased from Santa Cruz. bTSH, Anti-GFP antibody, Trimethylamine-N-oxide (TMAO), DMSO and MTT were purchased from Sigma-Aldrich.

\section{In silico prediction}

The membrane expression and functionality of TSHR variants was assessed through the TSH receptor mutation database (6) at http://endokrinologie.uniklinikum-leipzig.de/tsh/frame.html and subsequent extensive literature research of references provided in the database. We obtained complete information for 55 variants that were then subjected to in silico predictions with 6 different tools: polyphen-2 (7) (genetics.bwh.harvard.edu/pph2/), PROVEAN (8) (provean.jcvi.org/), SIFT (9) (sift.jcvi.org/www/SIFT_enst_submit.html), PhD-SNP (10) (snps.biofold.org/phd-snp/phd-snp.html), PANTHER (11) (www.pantherdb.org/tools/csnp), SNPs\&GO (12)(snps.biofold.org/snps-and-go/snps-and-go.html). The TSHR variants were then assigned as damaging (more than $50 \%$ of predictions concordant as functionally damaging or impaired functionality) or not damaging (50\% or more of predictions concordant as neutral or benign). 


\section{Cell culture, transfection, treatments and viability assay}

COS-7 cells were grown in DMEM medium (Gibco) supplemented with 10\% fetal bovine serum (Sigma Aldrich) and penicillin-streptomycin mixture (Sigma Aldrich). TSHR cloning and mutagenesis were described elsewhere (13). In cells transfected with pIRES2-EGFP vector, EGFP is an optimal internal normalizer of the transfection efficiency, without interfering with the TSHR maturation and expression.

pSVL plasmids containing WT, p.E34K and p.R46P TSHR variants were a kind gift of Dr. Tonacchera and have been previously described $(14,15)$. For all the experiments $3,5 \times 10^{5}$ cells per well were seeded in 6-well plates in order to obtain similar confluency in all the conditions, as confluency directly influences TSHR cleavage (16). After 24 hours, in each well $1 \mu \mathrm{g}$ of plasmid DNA was transiently transfected with Fugene Transfection Reagent (Promega) following the manufacturer's instructions. All samples were then analyzed 48 hours after transfection. For degradation inhibition or induction cells were treated with $10 \mu \mathrm{M} \mathrm{MG} 132,20 \mathrm{mM} \mathrm{NH}_{4} \mathrm{Cl}$ or $10 \mathrm{mM}$ LiCl 24 hours after transfection up until sample analysis. For chemical chaperone rescue, cells were cultured in medium containing 10\% glycerol or 100 mM TMAO from six hours after transfection up until sample analysis. Cell viability was tested at the indicated times with MTT assay, as previously described (17).

\section{Western blotting}

Cells were lysed in SDS sample buffer (62.5 mM Tris-HCl pH 6.8, 2\% sodium dodecyl sulfate) supplemented with protease, phosphatase and proteasome inhibitors.

Membrane preparations were obtained with Plasma Membrane Protein Extraction Kit (Abcam) following manufacturer's instructions. Total Cellular Membranes and Plasma Membranes fractions 
were then processed as the other samples. The samples were heated for $3 \mathrm{~min}$ at $95^{\circ} \mathrm{C}$ and sonicated. $40 \mu \mathrm{g}$ of protein extracts were then separated on NuPage 4-12\% Bis-Tris Gels (Thermo fisher) and transferred with iBlot System (Thermo fisher). Membranes were blocked with 5\% nonfat dry milk in TBS-T solution for 1 hour at room temperature and probed overnight at $4^{\circ} \mathrm{C}$ with monoclonal anti-TSHR antibody (clone 28.1) $(4,5)$ used as hybridoma supernatant and diluted to 1:20 ratio in the blocking buffer. Actin, E-cadherine and VDAC were used as loading control, GFP as transfection efficiency control. After washing, membranes were incubated for $1 \mathrm{~h}$ at room temperature in the presence of horseradish peroxidase-conjugated goat anti-mouse IgG secondary antibody (Merck Millipore) diluted to 1:10000 ratio in blocking buffer. Detection was performed utilizing Luminata Forte ECL (Merck Millipore).

Band intensity was quantified with ImageJ software (18), for each experiment 3 different exposures were quantified and averaged.

\section{Immunofluorescence and Confocal Microscopy}

Samples were washed with pre-warmed PBS and fixed by incubation in pre-warmed 2\% PFA in PBS solution for 10 minutes. After PBS washing, cells were permeabilized with $0.01 \%$ saponin in PBS for 5 minutes and then blocked with 5\% goat serum in PBS at room temperature for 1 hour. Samples were incubated overnight at $4^{\circ} \mathrm{C}$ with primary antibody solution (BA8 or 3G4) used as hybridoma supernatant and diluted to 1:4 ratio in blocking buffer. On the following day, cells were washed three times in PBS, and 1-hour incubation was performed with appropriated secondary antibody solution diluted to 1:100 in blocking buffer. Samples were mounted on microscope slides with $15 \mu$ of ProLong Gold Antifade Reagent with DAPI (Thermo fisher). Images were acquired with Nikon EclipseTi-E inverted microscope with IMA10X Argon-ion laser System by Melles Griot; all images were acquired with CFI Plan Apo VC 60X Oil (Nikon). 
For p.N432D expression pattern, 14 independent experiments for a total of 2018 transfected cells were visually analyzed and assigned to one of the four categories.

For late endosome-lysosome visualization, cells were incubated for 30 minutes with $1 \mu \mathrm{M}$ LysoTracker Red DND-99 (Thermo Fisher) prior to fixation. For colocalization quantification, 12 independent experiments for a total of 248 cells were analyzed with Nikon NIS Elements software.

For ER visualization, cells were incubated for 30 minutes with $1 \mu \mathrm{M}$ ER-Tracker Green (Thermo Fisher) prior to fixation. TSHR was labeled with a red secondary antibody and staining color was then reverted to green for TSHR and red for ER with Nikon NIS Elements software in order to have graphically homogeneous data display through all the panels. For colocalization quantification, 6 independent experiments for a total of 110 cells were analyzed with Nikon NIS Elements software.

\section{Flow cytometry}

Cells were detached in $\mathrm{Ca} 2+$ free phosphate buffered saline (PBS), and single cell suspension was obtained by gentle pipetting. Cell suspension was transferred to FACS tubes and incubated for 30 minutes on ice in the presence of BA8 or 3G4 anti-TSHR antibody used as hybridoma supernatant and diluted to 1:4 in FACS buffer (0.1\% BSA, 0.1\% sodium-azide in PBS solution). Cells were washed two times in FACS buffer and labeled for 30 minutes on ice in the dark with Alexa fluor conjugated goat anti-mouse IgG (Thermo Fisher), diluted to 1:100 in FACS buffer. Cells were washed in PBS and fixed in 2\% PFA-PBS. Measurements were performed with FACSCalibur flow cytometer (Becton Dickinson) on 10000 cells per sample. Six independent experiments were performed, each of them in duplicate. Data were analyzed with Flowing Software 2. For each experiment, transfected cells were gated based on the empty vector samples and mean fluorescence intensity was measured for each sample. 


\section{Functional assays}

For cAMP signaling pathway activity cells were transfected with TSHR variants together with the CRE-responsive firefly luciferase construct and Renilla luciferase 40:1 mix from Cignal CRE Reporter (luc) Kit (Quiagen) following manufacturer's instruction. Forty-eight hours after transfection cells were incubated with $0-100 \mathrm{U} / \mathrm{L}$ bovine TSH (bTSH) for 6 hours at $37^{\circ} \mathrm{C}$ and cAMP pathway activity was measured with Dual-Glo® Luciferase Assay System (Promega) following manufacturer's instruction. Samples' luminescence was measured with the Fluoroskan Ascent FL multiplate reader. Six independent experiments were performed.

Gq11/IP3 signaling pathway activity was measured with IP-One ELISA assay kit (Cisbio) following manufacturer's instructions. Briefly, cells were incubated for 1 hour at $37^{\circ} \mathrm{C}, 5 \% \mathrm{CO} 2$ with $100 \mathrm{U} / \mathrm{L}$ bTSH in stimulation buffer solution, followed by $30 \mathrm{~min}$ incubation in lysis buffer. 50 $\mathrm{uL}$ of each lysate were then moved to ELISA plate and reaction developed following manufacturer's instruction. Colorimetric reaction was red at 450nm using ELx800 Absorbance Microplate Reader. Six independent experiments were performed.

\section{Statistical analysis}

All experiments were independently repeated at least three times, as indicated in the text and figure legends. After normal distribution and variance similarity evaluation, two-sided unpaired t-test (eventual Welch's correction for groups with different variances), one-way ANOVA with Bonferroni post-hoc test, Kruskal-Wallis H test with Dunns post hoc test and Chi-square test were used as indicated in figures' legend.

For concentration-effect curves of Gs/cAMP signaling a log(agonist) vs. normalized response Variable slope equation was used for curve interpolation and parameters definition. 
For confocal experiments, the degree of colocalization was quantified through Pearson's correlation coefficient, as measured with Nikon NIS Elements software. Correlation was defined as strong with Pearson's correlation coefficient bigger than 0.8 , moderate when bigger than 0.5 and weak when bigger than 0.2 . In all figures data are shown as mean \pm SEM, analyzed using GraphPad Prism 5 software and significance expressed as $\mathrm{P}$ values $(* \mathrm{p}<0.05, * * \mathrm{p}<0.01, * * * \mathrm{p}<0.001)$ 


\section{References to supplementary methods}

1. Costagliola S, Rodien P, Many MC, et al. 1998 Genetic immunization against the human thyrotropin receptor causes thyroiditis and allows production of monoclonal antibodies recognizing the native receptor. J Immunol 160:1458-65.

2. Costagliola S, Khoo D, Vassart G 1998 Production of bioactive amino-terminal domain of the thyrotropin receptor via insertion in the plasma membrane by a glycosylphosphatidylinositol anchor. FEBS Lett 436:427-33.

3. Alberti L, Proverbio MC, Costagliola S, et al. 2001 A novel germline mutation in the TSH receptor gene causes non-autoimmune autosomal dominant hyperthyroidism. Eur J Endocrinol 145:249-54.

4. Urizar E, Montanelli L, Loy T, et al. 2005 Glycoprotein hormone receptors: link between receptor homodimerization and negative cooperativity. EMBO J 24:1954-64.

5. Minich WB, Lenzner C, Morgenthaler NG 2004 Antibodies to TSH-receptor in thyroid autoimmune disease interact with monoclonal antibodies whose epitopes are broadly distributed on the receptor. Clin Exp Immunol 136:129-36.

6. Lüblinghoff J, Nebel IT, Huth S, et. al R 2012 The leipzig thyrotropin receptor mutation database: update 2012. Eur Thyroid J 1:209-10.

7. Adzhubei IA, Schmidt S, Peshkin L, et al. 2010 A method and server for predicting damaging missense mutations. Nat Methods 7:248-9.

8. Choi Y, Sims GE, Murphy S et al. 2012 Predicting the Functional Effect of Amino Acid Substitutions and Indels. PLoS One 7:e46688.

9. Kumar P, Henikoff S, Ng PC 2009 Predicting the effects of coding non-synonymous variants on protein function using the SIFT algorithm. Nat Protoc 4:1073-1081. 
10. Capriotti E, Calabrese R, Casadio R 2006 Predicting the insurgence of human genetic diseases associated to single point protein mutations with support vector machines and evolutionary information. Bioinformatics 22:2729-2734.

11. Tang H, Thomas PD 2016 PANTHER-PSEP: predicting disease-causing genetic variants using position-specific evolutionary preservation. Bioinformatics 32:2230-2232.

12. Capriotti E, Calabrese R, Fariselli Pet al. 2013 WS-SNPs\&amp;GO: a web server for predicting the deleterious effect of human protein variants using functional annotation. BMC Genomics 14 Suppl 3:S6.

13. Lábadi Á, Grassi ES, Gellén B et al. L 2015 Loss-of-Function Variants in a Hungarian Cohort Reveal Structural Insights on TSH Receptor Maturation and Signaling. J Clin Endocrinol Metab 100:E1039-45.

14. Agretti P, De Marco G, Capodanno A et al. 2007 A fast method to detect cell surface expression of thyrotropin receptor (TSHr): The microchip flow cytometry analysis. Thyroid 17:861-868.

15. De Marco G, Agretti P, Camilot Met al. 2009 Functional studies of new TSH receptor (TSHr) mutations identified in patients affected by hypothyroidism or isolated hyperthyrotrophinaemia. Clin Endocrinol (Oxf) 70:335-338.

16. Vu M-TH, Radu A, Ghinea N 2009 The cleavage of thyroid-stimulating hormone receptor is dependent on cell-cell contacts and regulates the hormonal stimulation of phospholipase c. J Cell Mol Med 13:2253-60.

17. Grassi ES, Vezzoli V, Negri I et al. 2015 SP600125 has a remarkable anticancer potential against undifferentiated thyroid cancer through selective action on ROCK and p53 pathways. Oncotarget 6:36383-99. 
18. Schindelin J, Arganda-Carreras I, Frise E et al. 2012 Fiji: An open-source platform for biological-image analysis. Nat Methods. 2012;9:676-682. 
1 Supplementary materials to Grassi ES et al (running title: TSHR variants degradation and 2 functional rescue)

A
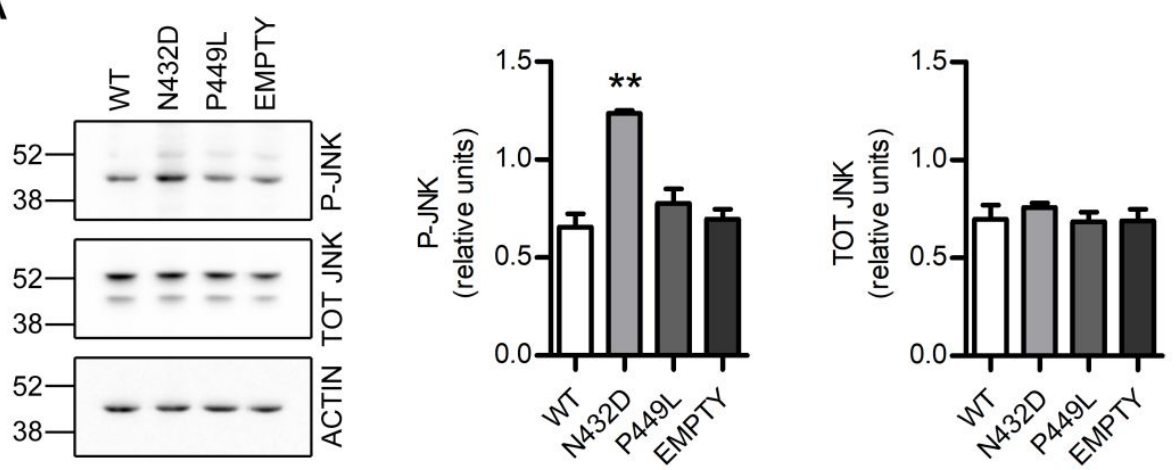

B
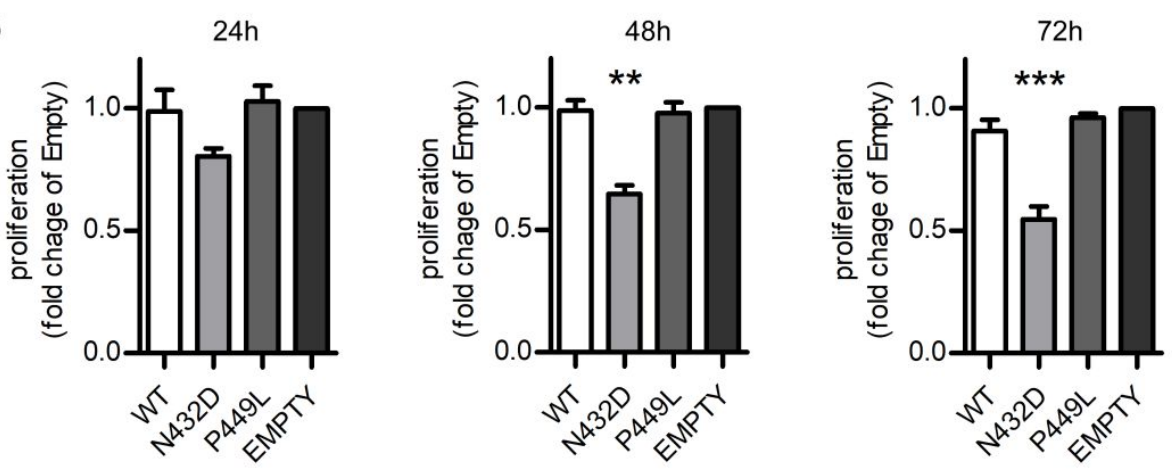

Supplementary Figure 1: p.N432D induces JNK phosphorylation and reduces cell viability.

A: representative images of western blotting and relative densitometric quantification showing JNK

$1 / 2$ phosphorylation and total protein levels in cell transfected with different TSHR variants.

B: proliferation assays showing cells viability at 24,48 and $72 \mathrm{~h}$ post transfection of the different TSHR variants.

9 Statistical analysis: A, B n=3. Statistical significance was determined with non parametric KruskalWallis H test followed by Dunn's post hoc test. 

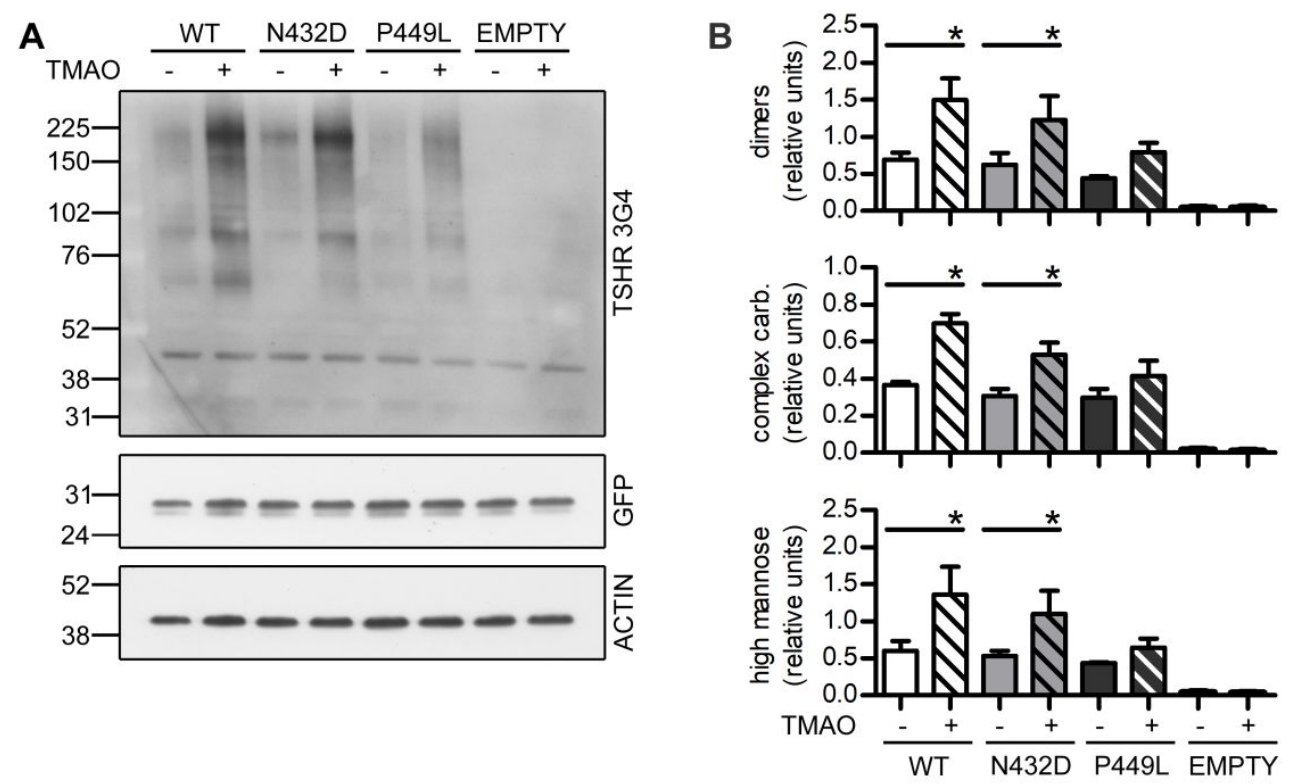

C
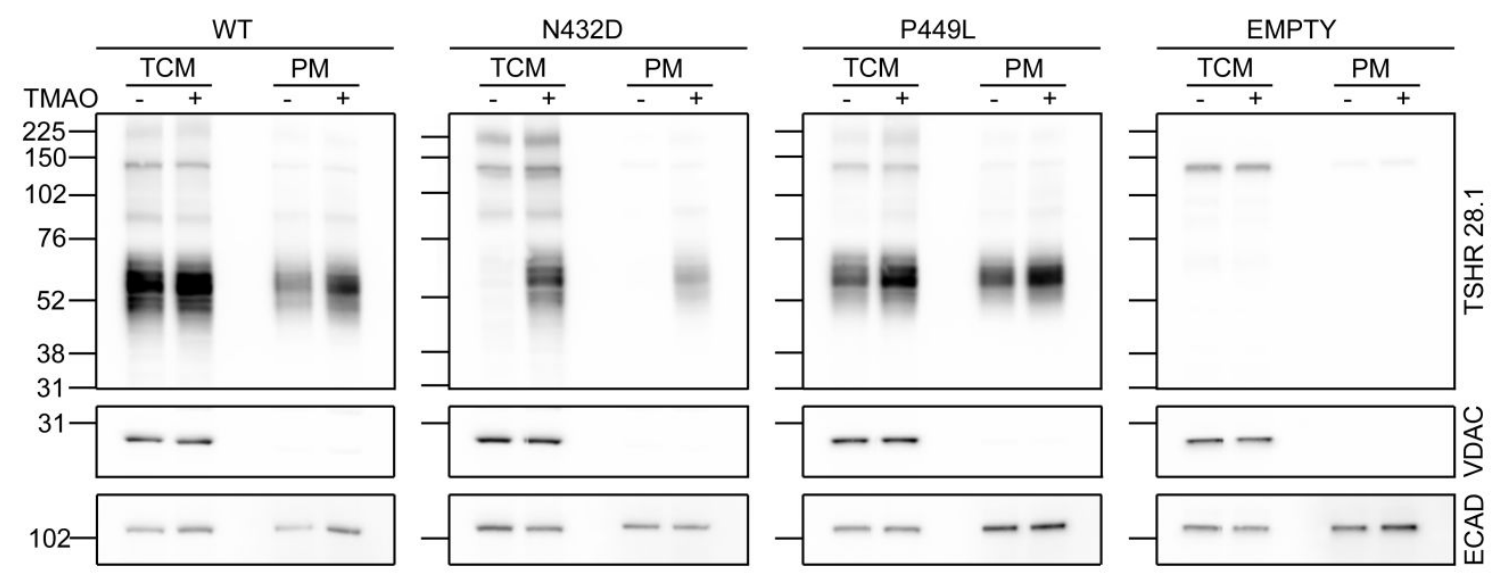

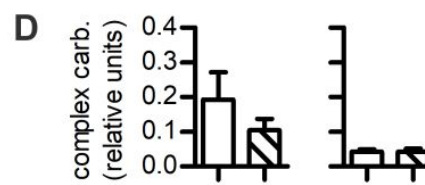
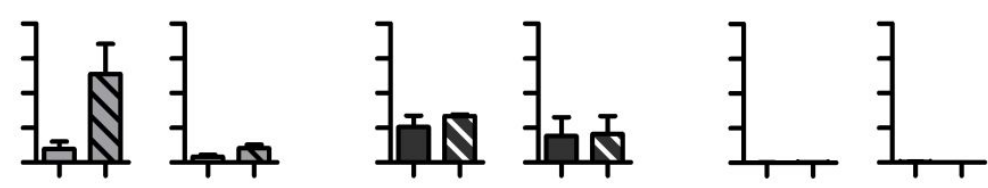

هon
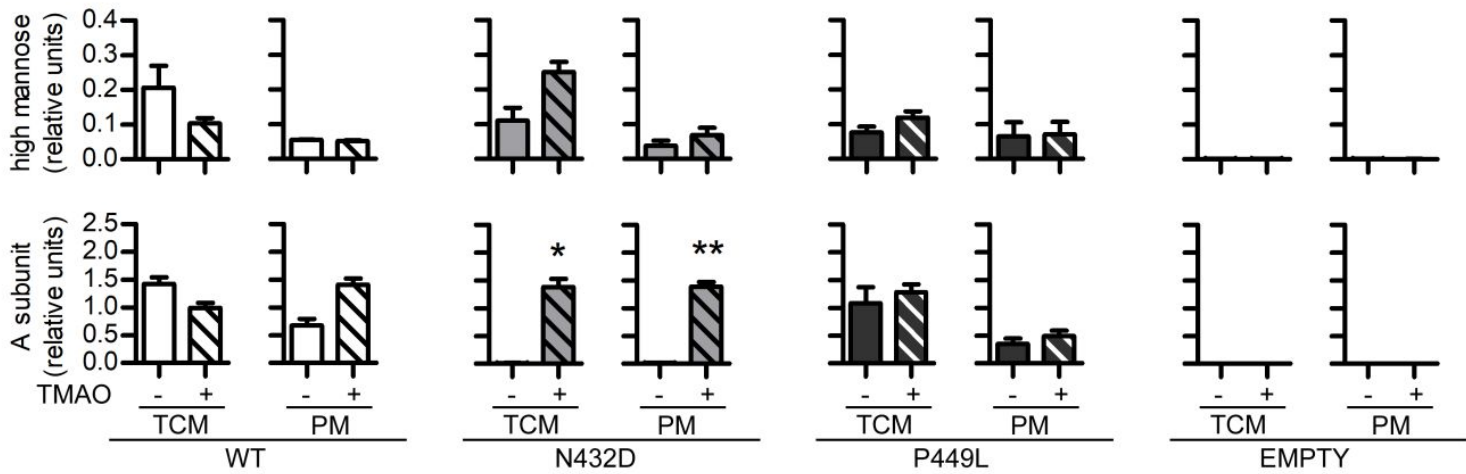
14 Supplementary figure 2: TMAO treatments promote p.N432D homodimerization and A-

15

\section{subunit expression on plasma membrane.}

A: representative image of TSHR western blot performed with $3 \mathrm{G} 4$ antibody (reblot of Fig. 4A) showing effects of TMAO treatment on high molecular weight high mannose dimers.

B: densitometric quantification of western blot experiments showing high mannose dimers, complex carbohydrates and high mannose forms of TSHR without and after TMAO treatment.

C: representative images of western blotting experiments showing the expression and maturation of the TSHR variants in Total Cell Membranes (TCM) and Plasma Membranes (PM) preparations. TSHR was stained with 28.1 antibody, VDAC was used as intracellular membranes control and Ecadherine (ECAD) was used as plasma membrane control.

D: densitometric quantification of western blot experiments showing complex carbohydrates, high mannose and A-subunit forms of TSHR without and with TMAO treatment. 



Supplementary figure 3: glycerol treatment does not affect TSHR maturation.

29 Representative images of 3 independent western blotting experiment showing the expression and

30 maturation of the TSHR variants without and after treatment with $10 \%$ glycerol. TSHR was stained

31 with 28.1 antibody. GFP was used as transfection efficiency control and actin was used as loading control. 

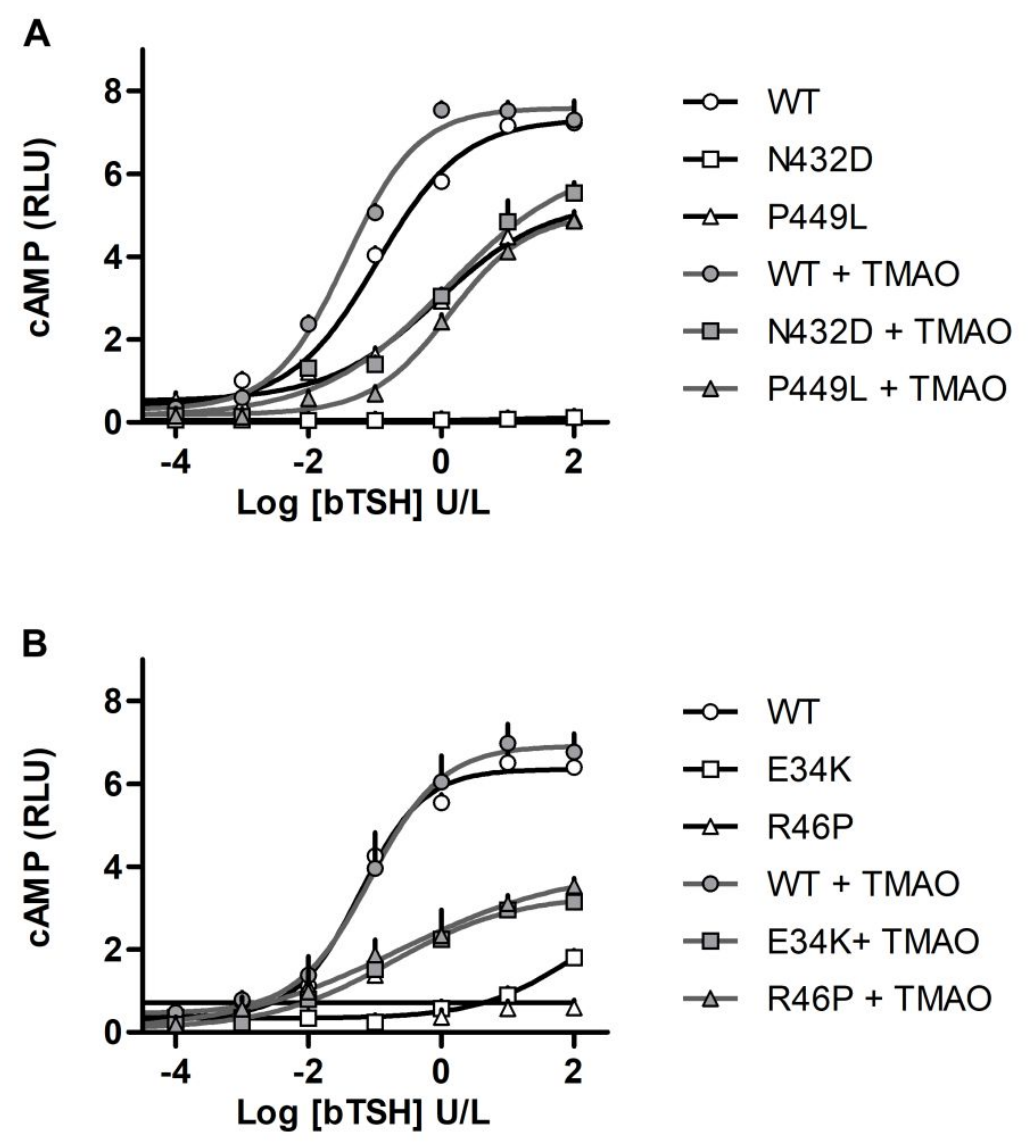

35 Supplementary figure 4: TSHR variants concentration-effect curves.

36 A, B: dose-response curves for Gs/cAMP signaling of TSHR WT, p.N432D and p.P449L variants upon normal conditions and after TMAO treatment. The effect is represented as percentage of TMAO treated WT maximal stimulation and expressed as Luciferase/Renilla RLU. 


\begin{tabular}{|c|c|c|c|c|c|c|c|c|c|}
\hline & &  & 1 & VSI & ICO DAT & & & IN VII & $O$ DATA \\
\hline $\begin{array}{c}\text { TSHR } \\
\text { varian } \\
\mathbf{t}\end{array}$ & $\begin{array}{l}\text { poly } \\
\text { phen }\end{array}$ & $\begin{array}{c}\text { PROVE } \\
\text { AN }\end{array}$ & $\begin{array}{c}\text { SIF } \\
\text { T }\end{array}$ & $\begin{array}{l}\text { Ph } \\
\text { D- } \\
\text { SN } \\
\text { P }\end{array}$ & $\begin{array}{c}\text { PANTH } \\
\text { ER }\end{array}$ & $\begin{array}{c}\text { SNPs } \\
\text { \& } \\
\text { GO }\end{array}$ & $\begin{array}{c}\text { TOTAL } \\
\text { PREDICTIO } \\
\mathbf{N}\end{array}$ & $\begin{array}{c}\text { Signaling } \\
(\% \text { WT) }\end{array}$ & $\begin{array}{c}\text { Membrane } \\
\text { expression } \\
\text { (\% WT) }\end{array}$ \\
\hline $\mathrm{P} 27 \mathrm{~T}$ & $\mathrm{~N}$ & $\mathrm{~N}$ & $\mathrm{~N}$ & $\mathrm{~N}$ & $\mathrm{D}$ & $\mathrm{N}$ & $\mathrm{N}$ & 80,00 & 80,0 \\
\hline C31P & $\mathrm{D}$ & D & D & $\mathrm{N}$ & $\mathrm{N}$ & $\mathrm{N}$ & $\mathrm{N}$ & 0,00 & 0,0 \\
\hline E34K & $\mathrm{N}$ & $\mathrm{N}$ & $\mathrm{N}$ & $\mathrm{N}$ & D & $\mathrm{N}$ & $\mathrm{N}$ & 45,00 & 40,0 \\
\hline D36H & $\mathrm{D}$ & $\mathrm{N}$ & $\mathrm{N}$ & $\mathrm{N}$ & $\mathrm{D}$ & $\mathrm{N}$ & $\mathrm{N}$ & 100,00 & 90,0 \\
\hline C41S & $\mathrm{D}$ & D & $\mathrm{N}$ & $\mathrm{D}$ & $\mathrm{D}$ & $\mathrm{D}$ & $\mathrm{D}$ & 0,00 & 0,0 \\
\hline R46P & $\mathrm{N}$ & $\mathrm{N}$ & $\mathrm{N}$ & $\mathrm{D}$ & $\mathrm{N}$ & $\mathrm{N}$ & $\mathrm{N}$ & 0,00 & 5,0 \\
\hline $\mathrm{P} 52 \mathrm{~T}$ & $\mathrm{~N}$ & $\mathrm{~N}$ & $\mathrm{~N}$ & $\mathrm{~N}$ & D & $\mathrm{N}$ & $\mathrm{N}$ & 100,00 & 90,0 \\
\hline P68S & $\mathrm{D}$ & $\mathrm{D}$ & $\mathrm{N}$ & $\mathrm{D}$ & $\mathrm{N}$ & $\mathrm{N}$ & $\mathrm{N}$ & 80,00 & 50,0 \\
\hline Q90P & $\mathrm{D}$ & $\mathrm{N}$ & $\mathrm{D}$ & $\mathrm{D}$ & $\mathrm{D}$ & $\mathrm{D}$ & $\mathrm{D}$ & 45,00 & 50,0 \\
\hline R109Q & D & $\mathrm{N}$ & $\mathrm{N}$ & $\mathrm{N}$ & $\mathrm{N}$ & $\mathrm{N}$ & & 75,00 & 10,0 \\
\hline G132R & $\mathrm{D}$ & $\mathrm{N}$ & $\mathrm{N}$ & $\mathrm{D}$ & $\mathrm{D}$ & $\mathrm{N}$ & $\mathrm{N}$ & 30,00 & 40,0 \\
\hline $\mathrm{T} 145 \mathrm{I}$ & $\mathrm{D}$ & $\mathrm{D}$ & $\mathrm{D}$ & $\mathrm{D}$ & $\mathrm{N}$ & $\mathrm{N}$ & $\mathrm{D}$ & 60,00 & 10,0 \\
\hline P162A & D & $\mathrm{N}$ & $\mathrm{N}$ & $\mathrm{N}$ & $\mathrm{N}$ & $\mathrm{N}$ & $\mathrm{N}$ & 80,00 & 70,0 \\
\hline P162L & $\mathrm{N}$ & $\mathrm{N}$ & $\mathrm{N}$ & $\mathrm{N}$ & $\mathrm{N}$ & $\mathrm{N}$ & $\mathrm{N}$ & 80,00 & 50,0 \\
\hline $\mathrm{I} 167 \mathrm{~N}$ & $\mathrm{D}$ & $\mathrm{D}$ & $\mathrm{D}$ & $\mathrm{D}$ & $\mathrm{D}$ & $\mathrm{D}$ & $\mathrm{D}$ & 0,00 & 0,0 \\
\hline $\mathrm{T} 179 \mathrm{I}$ & $\mathrm{N}$ & $\mathrm{N}$ & $\mathrm{N}$ & $\mathrm{N}$ & $\mathrm{N}$ & $\mathrm{N}$ & $\mathrm{N}$ & 0,00 & 30,0 \\
\hline $\mathrm{R} 183 \mathrm{~K}$ & $\mathrm{~N}$ & $\mathrm{~N}$ & $\mathrm{~N}$ & $\mathrm{~N}$ & $\mathrm{~N}$ & $\mathrm{~N}$ & $\mathrm{~N}$ & 80,00 & 100,0 \\
\hline A204V & D & $\mathrm{N}$ & $\mathrm{N}$ & $\mathrm{N}$ & $\mathrm{N}$ & $\mathrm{N}$ & $\mathrm{N}$ & 50,00 & 80,0 \\
\hline G245S & $\mathrm{D}$ & D & $\mathrm{D}$ & $\mathrm{D}$ & $\mathrm{D}$ & $\mathrm{D}$ & $\mathrm{D}$ & 20,00 & 60,0 \\
\hline
\end{tabular}

Supplementary table 1: in silico prediction of TSHR mutants and the respective in vitro data.

In silico prediction of mutation effects were obtained as described in material and methods session.

TSHR variants were assigned as damaging (D) when predicted to be functionally damaging or probable functionally damaging, they were assigned as non-damaging $(\mathrm{N})$ when they were predicted to be benign or neutral. In vitro data were obtained from extensive literature review and

are reported as percentage of WT TSHR with a 5\% approximation. 


\begin{tabular}{|c|c|c|c|c|c|c|c|c|c|}
\hline $\mathrm{R} 248 \mathrm{~S}$ & $\mathrm{~N}$ & $\mathrm{~N}$ & $\mathrm{~N}$ & $\mathrm{~N}$ & $\mathrm{~N}$ & $\mathrm{~N}$ & $\mathrm{~N}$ & 0,00 & 10,0 \\
\hline $\mathrm{L} 252 \mathrm{P}$ & $\mathrm{D}$ & $\mathrm{D}$ & $\mathrm{D}$ & $\mathrm{D}$ & $\mathrm{D}$ & $\mathrm{D}$ & $\mathrm{D}$ & 20,00 & 25,0 \\
\hline P264S & $\mathrm{D}$ & $\mathrm{D}$ & $\mathrm{D}$ & $\mathrm{N}$ & $\mathrm{N}$ & $\mathrm{N}$ & $\mathrm{N}$ & 10,00 & 40,0 \\
\hline $\mathrm{R} 310 \mathrm{C}$ & $\mathrm{D}$ & $\mathrm{N}$ & $\mathrm{D}$ & $\mathrm{D}$ & $\mathrm{N}$ & $\mathrm{N}$ & $\mathrm{D}$ & 25,00 & 70,0 \\
\hline Q324H & $\mathrm{D}$ & $\mathrm{N}$ & $\mathrm{N}$ & $\mathrm{N}$ & $\mathrm{N}$ & $\mathrm{N}$ & $\mathrm{N}$ & 25,00 & 20,0 \\
\hline $\begin{array}{l}\text { C390 } \\
\mathrm{W}\end{array}$ & D & D & $\mathrm{D}$ & D & $\mathrm{D}$ & D & $\mathrm{D}$ & 80,00 & 100,0 \\
\hline $\mathrm{D} 403 \mathrm{~N}$ & $\mathrm{D}$ & $\mathrm{D}$ & $\mathrm{D}$ & $\mathrm{D}$ & $\mathrm{D}$ & $\mathrm{D}$ & $\mathrm{D}$ & 70,00 & 60,0 \\
\hline D410N & $\mathrm{D}$ & $\mathrm{D}$ & $\mathrm{D}$ & $\mathrm{D}$ & $\mathrm{D}$ & $\mathrm{D}$ & $\mathrm{D}$ & 20,00 & 50,0 \\
\hline $\mathrm{N} 432 \mathrm{D}$ & $\mathrm{D}$ & $\mathrm{D}$ & $\mathrm{D}$ & $\mathrm{N}$ & $\mathrm{N}$ & $\mathrm{B}$ & $\mathrm{N}$ & 0,00 & 0,0 \\
\hline P449L & $\mathrm{D}$ & $\mathrm{D}$ & $\mathrm{D}$ & $\mathrm{D}$ & $\mathrm{D}$ & $\mathrm{D}$ & $\mathrm{D}$ & 50,00 & 120,0 \\
\hline $\mathrm{R} 450 \mathrm{H}$ & $\mathrm{D}$ & $\mathrm{D}$ & $\mathrm{D}$ & $\mathrm{D}$ & $\mathrm{D}$ & $\mathrm{D}$ & $\mathrm{D}$ & 30,00 & 50,0 \\
\hline Y466C & $\mathrm{D}$ & $\mathrm{D}$ & $\mathrm{D}$ & $\mathrm{D}$ & $\mathrm{D}$ & $\mathrm{D}$ & $\mathrm{D}$ & 40,00 & 60,0 \\
\hline L467P & $\mathrm{D}$ & $\mathrm{D}$ & $\mathrm{D}$ & $\mathrm{D}$ & $\mathrm{D}$ & $\mathrm{D}$ & $\mathrm{D}$ & 0,00 & 0,0 \\
\hline V473I & $\mathrm{D}$ & $\mathrm{N}$ & $\mathrm{D}$ & $\mathrm{N}$ & $\mathrm{N}$ & $\mathrm{N}$ & $\mathrm{N}$ & 60,00 & 90,0 \\
\hline T477I & $\mathrm{D}$ & $\mathrm{D}$ & $\mathrm{D}$ & $\mathrm{D}$ & $\mathrm{D}$ & $\mathrm{D}$ & $\mathrm{D}$ & 0,00 & 10,0 \\
\hline $\begin{array}{l}\text { W488 } \\
\mathrm{R}\end{array}$ & $\mathrm{D}$ & $\mathrm{D}$ & $\mathrm{D}$ & $\mathrm{D}$ & $\mathrm{D}$ & $\mathrm{D}$ & $\mathrm{D}$ & 10,00 & 10,0 \\
\hline Q489H & $\mathrm{D}$ & $\mathrm{D}$ & $\mathrm{D}$ & $\mathrm{D}$ & $\mathrm{D}$ & $\mathrm{D}$ & $\mathrm{D}$ & 0,00 & 80,0 \\
\hline G498S & $\mathrm{D}$ & $\mathrm{D}$ & $\mathrm{D}$ & $\mathrm{D}$ & $\mathrm{N}$ & $\mathrm{N}$ & $\mathrm{D}$ & 10,00 & 0,0 \\
\hline R519C & $\mathrm{D}$ & $\mathrm{D}$ & $\mathrm{D}$ & $\mathrm{D}$ & $\mathrm{D}$ & $\mathrm{D}$ & $\mathrm{D}$ & 20,00 & 50,0 \\
\hline R519G & $\mathrm{D}$ & $\mathrm{D}$ & $\mathrm{D}$ & $\mathrm{D}$ & $\mathrm{D}$ & $\mathrm{D}$ & $\mathrm{D}$ & 0,00 & 10,0 \\
\hline F525L & $\mathrm{D}$ & $\mathrm{D}$ & $\mathrm{D}$ & $\mathrm{D}$ & $\mathrm{N}$ & $\mathrm{N}$ & $\mathrm{D}$ & 30,00 & 55,0 \\
\hline $\begin{array}{l}\text { M527 } \\
\text { T }\end{array}$ & $\mathrm{D}$ & $\mathrm{D}$ & $\mathrm{D}$ & $\mathrm{D}$ & $\mathrm{N}$ & $\mathrm{N}$ & $\mathrm{D}$ & 30,00 & 60,0 \\
\hline $\begin{array}{l}\text { R531 } \\
\text { W }\end{array}$ & $\mathrm{D}$ & $\mathrm{D}$ & $\mathrm{D}$ & $\mathrm{D}$ & $\mathrm{D}$ & D & $\mathrm{D}$ & 0,00 & 65,0 \\
\hline $\begin{array}{l}\text { W546 } \\
\text { G }\end{array}$ & $\mathrm{D}$ & $\mathrm{D}$ & $\mathrm{D}$ & $\mathrm{D}$ & $\mathrm{D}$ & $\mathrm{D}$ & $\mathrm{D}$ & 20,00 & 60,0 \\
\hline $\mathrm{A} 553 \mathrm{~T}$ & $\mathrm{D}$ & $\mathrm{D}$ & $\mathrm{D}$ & $\mathrm{D}$ & $\mathrm{D}$ & $\mathrm{D}$ & $\mathrm{D}$ & 50,00 & 20,0 \\
\hline P556R & $\mathrm{D}$ & $\mathrm{D}$ & $\mathrm{D}$ & $\mathrm{D}$ & $\mathrm{D}$ & $\mathrm{D}$ & $\mathrm{D}$ & 0,00 & 10,0 \\
\hline $\mathrm{I} 583 \mathrm{~T}$ & $\mathrm{D}$ & $\mathrm{D}$ & $\mathrm{D}$ & $\mathrm{N}$ & $\mathrm{D}$ & $\mathrm{N}$ & $\mathrm{D}$ & 50,00 & 80,0 \\
\hline A593V & $\mathrm{D}$ & $\mathrm{D}$ & $\mathrm{D}$ & $\mathrm{N}$ & $\mathrm{D}$ & $\mathrm{D}$ & $\mathrm{D}$ & 100,00 & 40,0 \\
\hline C600R & $\mathrm{D}$ & $\mathrm{D}$ & $\mathrm{D}$ & $\mathrm{D}$ & $\mathrm{D}$ & $\mathrm{D}$ & $\mathrm{D}$ & 0,00 & 0,0 \\
\hline
\end{tabular}




\begin{tabular}{|c|c|c|c|c|c|c|c|c|c|}
\hline Y601H & D & D & D & D & D & D & D & 30,00 & 40,0 \\
\hline T607I & D & D & D & D & N & N & D & 100,00 & 80,0 \\
\hline R609Q & D & N & N & D & D & N & N & 100,00 & 90,0 \\
\hline P639L & D & D & D & D & D & D & D & 0,00 & 90,0 \\
\hline L653V & D & D & D & D & N & N & D & 70,00 & 80,0 \\
\hline V689G & D & D & D & D & D & N & D & 35,00 & 55,0 \\
\hline D727E & N & N & N & N & N & N & N & 100,00 & 90,0 \\
\hline
\end{tabular}

47

48

49

50

51 